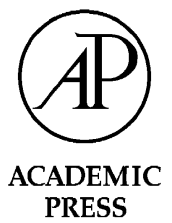

Available online at www.sciencedirect.com

\title{
Metabolic flux analysis of xylose metabolism in recombinant Saccharomyces cerevisiae using continuous culture
}

\author{
Juha-Pekka Pitkänen, ${ }^{1}$ Aristos Aristidou, ${ }^{2}$ Laura Salusjärvi, \\ Laura Ruohonen, ${ }^{*}$ and Merja Penttilä \\ VTT Biotechnology, P.O. Box 1500, FIN-02044 VTT, Finland \\ Received 9 July 2002; accepted 13 November 2002
}

\begin{abstract}
This study focused on elucidating metabolism of xylose in a Saccharomyces cerevisiae strain that overexpresses xylose reductase and xylitol dehydrogenase from Pichia stipitis, as well as the endogenous xylulokinase. The influence of xylose on overall metabolism was examined supplemented with low glucose levels with emphasis on two potential bottlenecks; cofactor requirements and xylose uptake. Results of metabolic flux analysis in continuous cultivations show changes in central metabolism due to the cofactor imbalance imposed by the two-step oxidoreductase reaction of xylose to xylulose. A comparison between cultivations on 27:3 g/L xylose-glucose mixture and $10 \mathrm{~g} / \mathrm{L}$ glucose revealed that the NADPH-generating flux from glucose-6-phosphate to ribulose5-phosphate was almost tenfold higher on xylose-glucose mixture and due to the loss of carbon in that pathway the total flux to pyruvate was only around $60 \%$ of that on glucose. As a consequence also the fluxes in the citric acid cycle were reduced to around $60 \%$. As the glucose level was decreased to $0.1 \mathrm{~g} / \mathrm{L}$ the fluxes to pyruvate and in the citric acid cycle were further reduced to $30 \%$ and $20 \%$, respectively. The results from in vitro and in vivo xylose uptake measurements showed that the specific xylose uptake rate was highest at the lowest glucose level, $0.1 \mathrm{~g} / \mathrm{L}$.
\end{abstract}

(C) 2003 Elsevier Science (USA). All rights reserved.

Keywords: Saccharomyces cerevisiae; Yeast; Xylose; Metabolic flux analysis; Ethanol; Xylitol

\section{Introduction}

Lignocellulosic materials are such an abundant and inexpensive resource that existing supplies could support the sustainable production of liquid transportation fuels. Xylose is the most abundant pentose sugar in the hemicellulose (ca. $25 \%$ of dry weight) of hardwoods and crop residues and its is second only to glucose in natural abundance. Thus, the efficient utilization of the xylose component of hemicellulose in addition to hexoses offers the opportunity to significantly reduce the cost of bioethanol production (Olsson and HahnHägerdal, 1996). Saccharomyces cerevisiae, which is one of the most prominent ethanol-production organisms using hexose sugars, has the drawback that it is unable

\footnotetext{
${ }^{*}$ Corresponding author.

E-mail address: laura.ruohonen@vtt.fi (L. Ruohonen).

${ }^{1}$ Current address: MediCel Ltd, Haartmaninkatu 8, FIN-00290 Helsinki, Finland

${ }^{2}$ Current address: Cargill Dow LLC, 15305 Minnetonka Boulevard, Minnetonka, MN 55345, USA
}

to utilize xylose. The initial steps of xylose utilization are as follows: xylose uptake through the cell membrane, xylose isomerization to xylulose and conversion of xylulose to glyceraldehyde-3-phosphate and fructose-6phosphate in pentose phosphate pathway (Prior and Kötter, 1997). S. cerevisiae can uptake xylose with the same systems it uses for glucose. However, xylose uptake is very inefficient compared to that of glucose. Reported $K_{\mathrm{m}}$ values for xylose transport vary between $130 \mathrm{mM}$ and 1.5 M (e.g., Kötter and Ciriacy, 1993; Singh and Mishra, 1995 and references therein, and our unpublished results), which are at least 5-200-fold higher vs. that for glucose. S. cerevisiae can catabolize xylulose (Jeffries, 1981; Ueng et al., 1981; Wang and Schneider, 1980), however, it cannot utilize xylose due to the absence of an active isomerization system (single or two-step) to convert xylose to xylulose (Jeffries, 1990). Attempts to introduce bacterial xylose isomerases in $S$. cerevisiae have met with some success so far (Walfridsson et al., 1996), but despite good efforts they have not yet provided a breakthrough. In yeast D-xylose is first 
reduced to xylitol by D-xylose reductase (XR) that uses either NADH or NADPH, but with a preference towards NADPH. Xylitol is then oxidized to D-xylulose with $\mathrm{NAD}^{+}$by xylitol dehydrogenase (XDH). The different cofactor specificities would lead to serious cofactor imbalance, if the cell would not be able to compensate it elsewhere in the metabolism. Before entering the pentose phosphate pathway xylulose is phosphorylated to xylulose 5-phosphate by xylulokinase (XK). In the pentose phosphate pathway non-oxidative reactions convert xylulose 5-phosphate to glyceraldehyde 3-phosphate and fructose 6-phosphate, which link the pentose phosphate pathway to glycolysis. The nonoxidative pentose phosphate pathway is a sequence of many reversible reactions which operate near equilibrium. Thus this step lacks irreversible reactions such as kinases with large differences in Gibbs free energies, which would drive the reactions efficiently forward (Jeffries, 1990).

The most common approach to construct xyloseutilizing recombinant $S$. cerevisiae strains has been the expression of XR- and XDH-encoding genes $X Y L 1$ and XYL2 from Pichia stipitis (Kötter et al., 1990; Walfridsson et al., 1997). Furthermore, overexpression of the endogenous XK improves xylose utilization, as has been demonstrated in recent studies (Eliasson et al., 2000; Toivari et al., 2001). Despite the successful expression of the three-enzyme set, $\mathrm{XR} / \mathrm{XDH} / \mathrm{XK}$, the rate of xylose utilization is still very low, and conversion yields poor due to xylitol accumulation. This has been attributed to limitations in all steps mentioned above.

It is important to notice how the limiting steps are all different in the way they affect the rate of xylose utilization. The reason why xylose uptake and the pentose phosphate pathway affect xylose utilization rate is due to their poor kinetic properties at the level of single reactions: high $K_{\mathrm{m}}$ values and low Gibbs free energies, respectively. On the other hand limitations caused by cofactor imbalance are related to the overall availability of the cofactors NADPH and NAD ${ }^{+}$, thus, requiring a whole-cell approach. One example of a whole-cell approach is the metabolic flux analysis. Basic metabolic flux analysis is not suitable to take into account the dynamic factors of the reactions such as $K_{\mathrm{m}}$ values or Gibbs free energies. But metabolic flux analysis is an ideal method for addressing the effects caused by the two-step oxidoreductase reaction of xylose to xylulose and the compensation of the cofactor imbalance. For the theory of metabolic flux analysis see Stephanopoulos et al. (1998).

Metabolic flux analysis has been applied extensively, including the quantification of metabolic fluxes in glucose-consuming yeast (Nissen et al., 1997; van Gulik and Heijnen, 1995), and more recently also for natural xylose-utilizing yeast (Granström et al., 2000) as well as genetically engineered $S$. cerevisiae (Wahlbom et al.,
2001; Wahlbom and Hahn-Hägerdal, 2002). Metabolic flux analysis has also been used to calculate theoretical yields for ethanol production from xylose-utilizing $S$. cerevisiae (Lee et al., 2001). Compared to previous studies our study focuses on aerobic conditions and to a series of low, decreasing glucose concentrations thus trying to maximize the specific xylose utilization to be able to show the true effects of xylose on cellular metabolism. The emphasis is on two potential bottlenecks; cofactor requirements and xylose uptake. Effects caused by cofactor requirements were studied using metabolic flux analysis in continuous cultivations while xylose uptake was studied with in vitro uptake assays. Furthermore, this study addresses the issue of aeration requirement for xylose utilization by $S$. cerevisiae by studying both aerobic and anaerobic conditions.

\section{Materials and methods}

\subsection{Strains and plasmids}

Two genetically modified $S$. cerevisiae yeast strains were used, which are here denoted as H2446 and H2490. The strains were based on strain CEN.PK2 (MAT $\alpha$, leu2-3/112, ura3-52, trp1-289, his3(delta)1, MAL2-8c, $S U C 2)$ (Boles et al., 1996). To this strain the $X Y L 1$ and $X Y L 2$ genes of $P$. stipitis, encoding xylose reductase $(\mathrm{XR})$ and xylitol dehydrogenase (XDH) respectively, were chromosomally integrated in the URA3 locus under constitutive $P G K 1$ and modified $A D H 1$ promoters (Ruohonen et al., 1995), respectively (Toivari et al., 2001). The strain was transformed with a multicopy YEplac195 plasmid (ura selection) (Gietz and Sugino, 1988 ), that carries the xylulokinase ( $X K S 1)$ gene from $S$. cerevisiae under the same constitutive $A D H 1$ promoter as $X Y L 2$. Additionally, the strains were transformed with an empty YEplac181 plasmid (leu selection) (Gietz and Sugino, 1988). This resulted in strain H2446. Furthermore, strain $\mathrm{H} 2490$ was obtained by curing $\mathrm{H} 2446$ for the histidine and tryptophan auxotrophies by integrating HIS3 and TRPI genes back to their respective loci. This was carried out in a series of steps described next. A functional HIS3 gene was isolated from plasmid pRS423 (Christianson et al., 1992) as a 1500 base pair (bp) fragment, and a functional TRP1 gene was isolated from plasmid pRS424 (Christianson et al., 1992) as a $1300 \mathrm{bp}$ fragment, after digestion with restriction enzyme $D r d I$. The strain whose auxotrophies were to be reversed (cured strain) was subsequently transformed with the above-mentioned fragments separately by the LiAc transformation method (Gietz et al., 1992; Hill et al., 1991) and plated on synthetic complete plates containing $20 \mathrm{~g} / \mathrm{L}$ glucose and omitting histidine for $H I S 3$ integration selection and tryptophan for TRPI integration selection. The $\operatorname{DrdI}$ fragment used in both 
cases had in addition to the functional HIS3 or TRPI also some vector sequence at both $5^{\prime}$ and $3^{\prime}$ ends. The correct integration was verified by amplifying the HIS3 or TRP1 region outside of the recombination site and sequencing the PCR fragment at $3^{\prime}$ and $5^{\prime}$ ends to verify that no vector sequence had integrated into the yeast chromosome.

\subsection{Cultivation media}

The liquid growth media contained $6.7 \mathrm{~g} / \mathrm{L}$ yeast nitrogen base (YNB) without amino acids (Difco) and varying amounts of D-glucose (Anala R BDH), D-xylose (Merck), or a mixture of the two. Concentrated sugar solutions were sterilized separately in an autoclave $\left(121^{\circ} \mathrm{C}, 20 \mathrm{~min}\right)$. The amino acids required for strain $\mathrm{H} 2466$ (L-histidine $0.058 \mathrm{~g} / \mathrm{L}$ and L-tryptophan $0.082 \mathrm{~g} /$ $\mathrm{L}$ Fluka) were filter-sterilized through a $0.22-\mu \mathrm{m}$ cellulose-acetate filter (Corning, USA). YNB solutions were sterilized by autoclaving for the chemostat cultures, but otherwise were filter-sterilized. Media for chemostat cultivations also contained $0.5 \mathrm{ml} / \mathrm{L}$ silicone antifoam (AnalaR BDH). The uniformly labeled U- ${ }^{13} \mathrm{C}$ $\mathrm{D}$-glucose, used in the labeling studies was purchased from Martek Biosciences Corporation.

\subsection{Cultivations}

The inocula were prepared in YNB with $20 \mathrm{~g} / \mathrm{L}$ glucose and appropriate amino acids for $\mathrm{H} 2446$ starting from plates. One colony was transferred into a $20-\mathrm{ml}$ tube with $5-\mathrm{ml}$ medium and incubated for $24 \mathrm{~h}$ at $30^{\circ} \mathrm{C}$ with an agitation of $200 \mathrm{rpm}$. The $5-\mathrm{ml}$ culture was transferred into a $250 \mathrm{ml}$ Erlenmeyer flask with $50-\mathrm{ml}$ medium and incubated for $20 \mathrm{~h}$ at $30^{\circ} \mathrm{C}$ with an agitation of $200 \mathrm{rpm}$. A sufficient number of flasks to give the amount of cells needed were combined, centrifuged $\left(4000 \mathrm{rpm}, 10 \mathrm{~min}\right.$ at $+4^{\circ} \mathrm{C}$ ), decanted and re-suspended in $50 \mathrm{ml}$ of the cultivation medium. The starting optical density $\left(\mathrm{OD}_{600}\right)$ in the cultivation was aimed to be around one.

Shake flask cultivations were performed at a temperature of $30^{\circ} \mathrm{C}$ in $250-\mathrm{ml}$ Erlenmeyer flasks. Aerobic cultivation conditions were achieved using a $60-\mathrm{ml}$ cultivation volume at an agitation speed of $200 \mathrm{rpm}$.

The chemostat cultivations were carried out in $1.8 \mathrm{~L}$ Chemap CNF fermenters (Chemap AG, Switzerland) at a temperature of $30^{\circ} \mathrm{C}$, agitation speed $500 \mathrm{rpm}$ and $\mathrm{pH}$ of 5.5 adjusted with $1 \mathrm{M} \mathrm{KOH}$ and $1 \mathrm{M} \mathrm{H}_{3} \mathrm{PO}_{4}$. The total gas flow rate was $0.5 \mathrm{vvm}$, adjusted with two mass flow controllers (Bronkhorst High-Tech B.V., Netherlands), one for air under aerobic conditions $\left(+\mathrm{O}_{2}\right)$ and the other for nitrogen $(99.999 \%$, quality 5.0, AGA, Finland) under anaerobic conditions $\left(-\mathrm{O}_{2}\right)$. The working volume was kept constant at $800 \mathrm{ml}$ with an overflow type system connected to a peristaltic pump (Watson
Marlow 101U/R, England) that continuously removed excess liquid. The dilution rate was maintained at $0.05 \mathrm{~h}^{-1}$ by feeding media with a second pump (Ismatec Reglo, Ismatec, Switzerland) at a fixed flow rate.

\subsection{Analytical procedures}

\subsubsection{Growth and extracellular product formation}

Cell density was followed optically (Shimadzu, Japan) at $600 \mathrm{~nm}\left(\mathrm{OD}_{600}\right)$ or gravimetrically by measuring the cell dry weight $(\mathrm{CDW}, \mathrm{g} / \mathrm{L})$. The $\mathrm{CDW}$ of $1 \mathrm{~g} / \mathrm{L}$ correlated to $\mathrm{OD}_{600}$ of $3.9 \pm 0.2$. For cell dry weight a known volume of culture sample was centrifuged $\left(4000 \mathrm{rpm} / 3000 \mathrm{~g}, 5 \mathrm{~min}\right.$ at $\left.+4^{\circ} \mathrm{C}\right)$ and washed with distilled water. The pellet was dried overnight at $105^{\circ} \mathrm{C}$ on pre-weighed dry weight cups and then weighed. The extracellular metabolite sample was obtained by filtering the supernatant through a $0.45 \mu \mathrm{m}$ syringe filter (MILLEX-GS, Millipore, France) and stored at $-20^{\circ} \mathrm{C}$. Glucose, xylose, xylitol, glycerol, acetate and ethanol were measured from filtered cultivation samples with a Waters HPLC system. The system consisted of a 510 pump, a 717 autosampler, an Aminex HPX-87H column (BioRad Labs, USA) maintained at $35^{\circ} \mathrm{C}$, a 410 refractive index (RI) detector and a 2487 dual wavelength UV detector $(210 \mathrm{~nm})$. Glucose and ethanol were analyzed also enzymatically with Cobas Mira autoanalyzer (Roche, Switzerland). The glucose assay was based on glucose-6-phosphate dehydrogenase and the ethanol assay on alcohol dehydrogenase (Boehringer Mannheim).

The composition of the fermenter off-gas was analyzed in-line using a QMG 421C quadrupole mass spectrometer (Balzers Pfeiffer Scandinavia AB, Sweden). The Balzers Quadstar 422 software was employed to calculate the percentage mole fractions of $\mathrm{O}_{2}, \mathrm{CO}_{2}$, $\mathrm{N}_{2}$ and Ar. The system was calibrated using the following two gas mixtures: $\mathrm{Ar} / \mathrm{O}_{2} / \mathrm{N}_{2}$ at the levels of $20 / 20 / 60 \mathrm{vol} \%$, and $\mathrm{CO}_{2} / \mathrm{Ar}$ at the levels of $3 / 97 \mathrm{vol} \%$ (Messer Griesheim, Germany).

\subsubsection{Xylose uptake assay in vitro}

The in vitro xylose uptake assay was adapted from the method described by Serrano (Serrano, 1977). The cells (H2446) were grown on pure xylose $(30 \mathrm{~g} / \mathrm{L})$ and on two glucose levels ( 1 and $20 \mathrm{~g} / \mathrm{L})$ both with and without xylose for $3 \mathrm{~h}$ in shake flasks. The cells were harvested, washed with $4^{\circ} \mathrm{C}$ distilled water and re-suspended in $100 \mathrm{mM}$ Tris-tartrate buffer (pH 5.5) to the final concentration of $50 \mathrm{~g} / \mathrm{L}(\mathrm{CDW})$. The assay was started by adding $50 \mu \mathrm{l}$ of the yeast suspension (ca. $2.5-\mathrm{mg}$ CDW) into $25 \mu \mathrm{l}$ of $450 \mathrm{mM}{ }^{14} \mathrm{C}$-labeled xylose (Batch $68,112 \mathrm{mCi} / \mathrm{mmol}$, Amersham Pharmacia Biotech) with a specific activity of $100 \mathrm{cpm} / \mathrm{nmol}$. The assay was performed at $30^{\circ} \mathrm{C}$ and was stopped after $30 \mathrm{~s}$ by adding $10 \mathrm{ml}$ of $0^{\circ} \mathrm{C}$ distilled water. The cells were filtered (0.45- $\mu \mathrm{m}$ HV, Membrane Filters, Millipore, France) and 
washed with $10 \mathrm{ml}$ of $0^{\circ} \mathrm{C}$ distilled water. The cells were transferred into $3.5 \mathrm{ml}$ of scintillation cocktail (OptiPhase, 'Hisafe'3, Wallac, Finland) and scintillated (Liquid Scintillation Counter, Wallac, Finland).

\subsection{Model description}

For the calculation of the in vivo metabolic fluxes a metabolic model was constructed consisting of 71 metabolites and 38 or 39 reactions for anaerobic or aerobic conditions, respectively. The metabolic network was based on the one described by Nissen and coworkers (Nissen et al., 1997), with a number of modifications including the addition of the xyloseutilizing reactions. The primary reactions (1-31) are presented in Fig. 1. All reactions and metabolites are presented in Appendix A. Reactions 1-10, 12-26 and 31 were derived directly from a basic biochemistry textbook (Stryer, 1995). Reaction 11, which represents the reaction catalyzed by mitochondrial alcohol dehydrogenase 3 (Adh3p), acts as an NADH shuttle between the cytosol and mitochondria (Bakker et al., 2000). In the model Adh3p operates in the direction of Adh1p using mitochondrial cofactors, but cytosolic substrates since ethanol and acetate can diffuse freely across mitochondrial membrane (Bakker et al., 2000). The recombinant reactions, the two-step oxidoreductase reaction of xylose and phosphorylation of xylulose are represented by the fluxes 27-30. It was assumed that the cofactor specificity of XR was equally divided between NADPH and NADH. This is not necessarily a good assumption, but in the case where the actual cytosolic ratio between intracellular NADPH and NADH is not known, it is not safe to assume that the in vitro determined cofactor specificity of the $P$. stipitis XR would be valid either. Furthermore, the ratio between NADPH- and NADHspecific XR-reaction cannot be let to settle freely by using two separate reactions in the model (Wahlbom et al., 2001), since this favors the NADH-specific reaction. However, the effect of changing the ratio of $\mathrm{NADPH}$ and NADH specificity was examined. It was also assumed that the uptake of xylose did not require

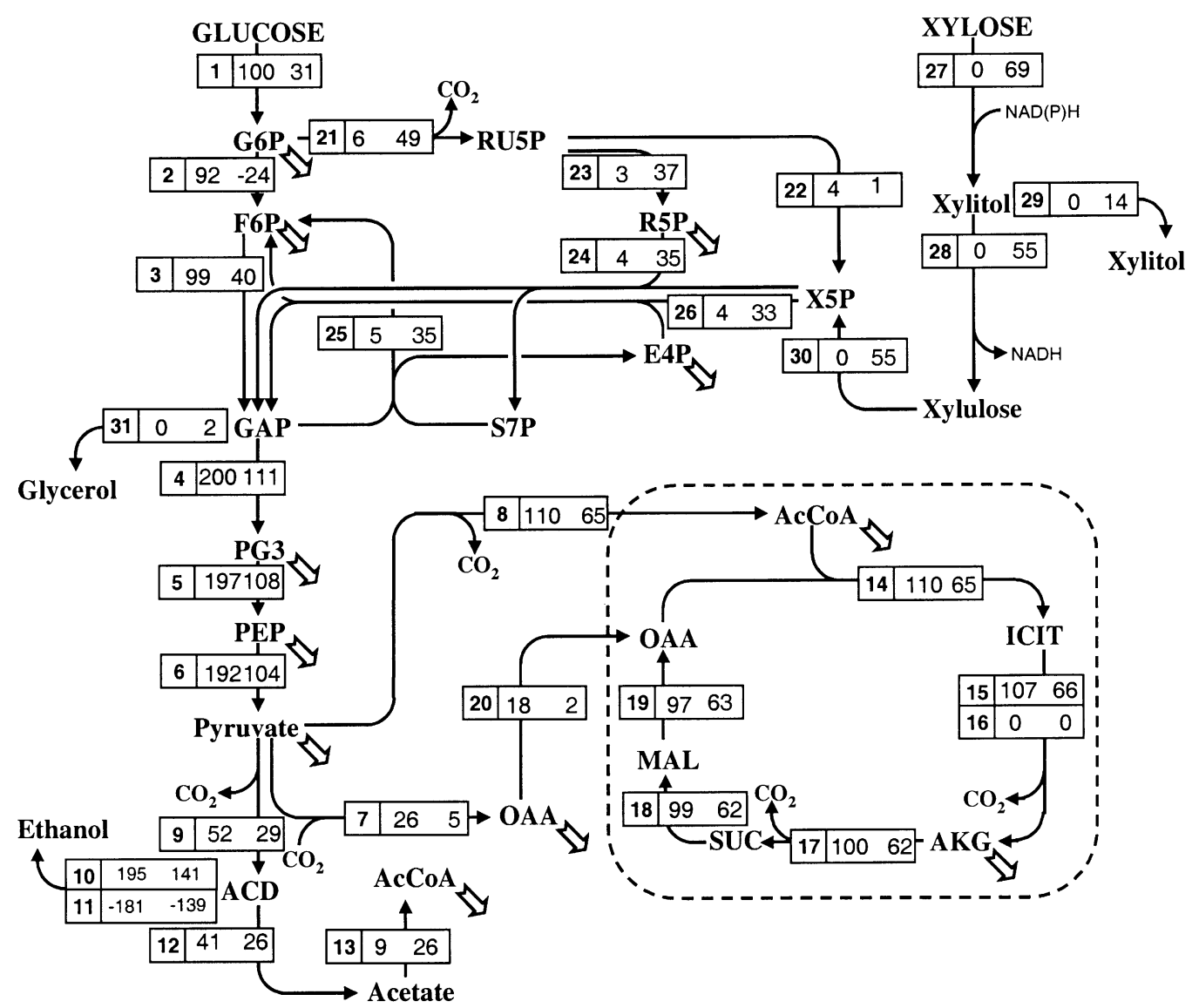

Fig. 1. The central carbon fluxes under aerobic conditions on glucose $(10 \mathrm{~g} / \mathrm{L})$ and on xylose-glucose mixture $(27: 3 \mathrm{~g} / \mathrm{L})$ in continuous chemostat cultivations at the dilution rate of $0.05 \mathrm{~h}^{-1}$. In each box, the left-hand number identifies the reaction step (see Appendix A), the middle number shows the flux on glucose and the right-hand number the flux on xylose-glucose mixture. The flux units are as a percentage of the total sugar utilization. In the glucose-only cultivation the specific glucose flux in was $1.20 \mathrm{mmol} / \mathrm{h} \mathrm{g}$. In the xylose-glucose cultivation glucose flux in was $0.32 \mathrm{mmol} / \mathrm{h} \mathrm{g}$ and the xylose flux in $0.72 \mathrm{mmol} / \mathrm{hg}$. Mitochondrial membrane is illustrated with a dashed line and the biomass-producing fluxes with the open arrows. 
ATP. Glyoxylate shunt is not included in the present model since our data from the isotopomer analysis suggest that the glyoxylate shunt was not operational in chemostat conditions even on xylose only (Maaheimo et al., manuscript in preparation). Reactions 32-36 accounted for the production of biomass components, synthesis of amino acids and protein polymerization, RNA and DNA, storage carbohydrates, and fatty acids. The reactions 32-36 were combined from 26 individual reactions adopted from Stephanopoulos et al. (1998) to yield five reactions. This approach maintains the focus on the 31 main fluxes for which the condition number of the stoichiometric matrix is relatively low $(<500)$. Reaction 37 captures the primary reactions of biomass formation assuming the elemental composition of $\mathrm{CH}_{1.82} \mathrm{O}_{0.58} \mathrm{~N}_{0.16}$ (Stephanopoulos et al., 1998) for biomass. Reaction 39 represents oxidative phosphorylation, with an assumed PO-ratio of 1 . In this work the ATP-balance could not be closed due to unknown factors of maintenance requirements and PO-ratio. The reaction 38 is implemented for maintenance purposes, dephosphorylating excess ATP back to ADP. The metabolites $m$ and fluxes $n$ were organized into a stoichiometric matrix $(M)$ with $m$ rows and $n$ columns. The rate vector $(r)$, with the dimensions of $m \times 1$, represents the accumulation of the compounds including the measured extracellular rates. The intracellular metabolite accumulation rates were assumed to be zero, as that should be the case under conditions of pseudosteady-state. The matrix notation of the system and the solution of the flux vector $x$ are as follow (\# is used to indicate a pseudo-inverse for the case where $M$ is not a square matrix):

$\underline{M} x=r \Rightarrow x=\underline{M}^{\#^{-1}} \cdot r$.

Additionally, either inequality of equality constraints were imposed for the flux vector $x$. The constraints can be used to establish the direction of a flux, i.e., irreversibility of the flux can be assigned, or the ratios between fluxes can be implemented. The matrix notation of the inequality constraint is as follows:

$\underline{C} x \leqslant d$.

Matrix $C$ determines whether the flux $x$ is constrained: if $C=0$ flux is not constrained and if $C=-1$ flux is higher than the constrained value $d$, which can have any rational values. Fluxes 6-9, 13-19, 21, 38 and 39 were constrained to be positive. The Matlab ${ }^{\mathrm{TM}}$ command LSQLIN was used to solve the above system for $x$ with constrained linear least squares for the system of Eqs. (1) and (2).

\section{Results}

\subsection{Comparison of xylose-glucose co-metabolism with glucose metabolism}

The strain $\mathrm{H} 2490$ was cultivated in a continuous system using a $27: 3 \mathrm{~g} / \mathrm{L}$ xylose-glucose mixture and for comparison a $10 \mathrm{~g} / \mathrm{L}$ glucose under both aerobic and anaerobic conditions for six to seven residence times until steady-state conditions were reached. Under all four conditions, for the last residence time $1 \mathrm{~g} / \mathrm{L}$ of the glucose in the media was replaced with $\mathrm{U}_{-}{ }^{13} \mathrm{C}$-labeled glucose for isotopomer analysis using NMR in order to further elucidate the biochemical network, as well as to quantify flux ratios at key metabolic nodes (Maaheimo et al., manuscript in preparation). The dilution rates, gas flow rates, cultivation liquid volumes, glucose and xylose concentrations in feed media and oxygen and carbon dioxide levels in gas feed are presented in Table 1. The concentrations $(\mathrm{g} / \mathrm{L})$ of glucose, xylose, xylitol, glycerol, acetate and ethanol in the vessel and levels (\%) of oxygen and carbon dioxide in the gas outflow at pseudo-steady states are presented in Table 2. Specific

Table 1

Dilution rates $(D)$, gas flow rates $\left(F_{\text {gas }}\right)$, liquid volumes $(V)$, concentrations of glucose and xylose in the feed media and levels of oxygen and carbon dioxide in the gas feed in the continuous cultivation of yeast $\mathrm{H} 2490$ on $27 \mathrm{~g} / \mathrm{L}$ xylose with $3 \mathrm{~g} / \mathrm{L}$ glucose (XYL/GLC3) and on $10 \mathrm{~g} / \mathrm{L}$ glucose (GLC) under aerobic and aerobic conditions and of yeast $\mathrm{H} 2446$ on $30 \mathrm{~g} / \mathrm{L}$ xylose with 1, 0.5, 0.1 and $0 \mathrm{~g} / \mathrm{L}$ glucose under aerobic conditions (XYL/GLC1; XYL/GLC0.5; XYL/GLC0.1; XYL)

\begin{tabular}{|c|c|c|c|c|c|c|c|}
\hline & $D\left(\mathrm{~h}^{-1}\right)$ & $F_{\text {gas }}(\mathrm{L} / \mathrm{min})$ & $V(\mathrm{~L})$ & Glucose $(\mathrm{g} / \mathrm{L})$ & Xylose (g/L) & $\mathrm{O}_{2}(\%)$ & $\mathrm{CO}_{2}(\%)$ \\
\hline \multicolumn{8}{|l|}{ Anaerobic } \\
\hline GLC & 0.047 & 0.51 & 0.80 & 10.2 & 0 & 0 & 0 \\
\hline XYL/GLC3 & 0.047 & 0.57 & 0.79 & 2.98 & 26.9 & 0 & 0 \\
\hline \multicolumn{8}{|l|}{ Aerobic } \\
\hline GLC & 0.048 & 0.55 & 0.80 & 11.1 & 0 & 20.10 & 0.071 \\
\hline XYL/GLC3 & 0.049 & 0.45 & 0.79 & 3.01 & 27.3 & 20.76 & 0.030 \\
\hline XYL/GLC1 & 0.050 & 0.40 & 0.79 & 0.97 & 28.8 & 20.59 & 0.066 \\
\hline XYL/GLC0.5 & 0.048 & 0.40 & 0.79 & 0.53 & 29.2 & 20.59 & 0.066 \\
\hline XYL/GLC0.1 & 0.045 & 0.40 & 0.79 & 0.12 & 29.6 & 20.59 & 0.066 \\
\hline XYL & 0.047 & 0.40 & 0.79 & 0 & 29.3 & 20.59 & 0.066 \\
\hline
\end{tabular}


Table 2

Concentrations of glucose, xylose, oxygen, carbon dioxide, biomass, xylitol, glycerol, acetate and ethanol in the continuous cultivation of yeast $\mathrm{H} 2490$ on $27 \mathrm{~g} / \mathrm{L}$ xylose with $3 \mathrm{~g} / \mathrm{L}$ glucose (XYL/GLC3) and on $10 \mathrm{~g} / \mathrm{L}$ glucose (GLC) under anaerobic and aerobic conditions and of yeast H2446 on $30 \mathrm{~g} / \mathrm{L}$ xylose with $1,0.5,0.1$ and $0 \mathrm{~g} / \mathrm{L}$ glucose under aerobic conditions (XYL/GLC1; XYL/GLC0.5; XYL/GLC0.1; XYL)

\begin{tabular}{llclllllll}
\hline & Glucose $(\mathrm{g} / \mathrm{L})$ & Xylose $(\mathrm{g} / \mathrm{L})$ & $\mathrm{O}_{2}(\%)$ & $\mathrm{CO}_{2}(\%)$ & Biomass $(\mathrm{g} / \mathrm{L})$ & Xylitol $(\mathrm{g} / \mathrm{L})$ & $\mathrm{Glycerol}(\mathrm{g} / \mathrm{L})$ & Acetate $(\mathrm{g} / \mathrm{L})$ & Ethanol $(\mathrm{g} / \mathrm{L})$ \\
\hline Anaerobic & & & & & & & & & \\
GLC & 0.06 & 0 & 0 & 0.320 & 0.59 & 0 & 1.11 & 0.25 & 3.05 \\
XYL/GLC3 & 0.19 & 24.7 & 0 & 0.098 & 0.23 & 1.13 & 0.42 & 0.15 & 1.42 \\
Aerobic & & & & & & & & & \\
GLC & 0.06 & 0 & 19.49 & 0.689 & 2.45 & 0 & 0 & 1.25 & 0.57 \\
XYL/GLC3 & 0.04 & 21.8 & 20.36 & 0.528 & 2.50 & 1.14 & 0.19 & 0.04 \\
XYL/GLC1 & 0.04 & 24.5 & 20.38 & 0.309 & 1.33 & 0.51 & 0.45 & 0.11 & 0.04 \\
XYL/GLC0.5 & 0.07 & 25.5 & 20.46 & 0.230 & 0.87 & 0.47 & 0.25 & 0.10 \\
XYL/GLC0.1 & 0.08 & 27.4 & 20.56 & 0.149 & 0.40 & 0.28 & 0.17 & 0.08 \\
XYL & 0 & 28.1 & 20.58 & 0.131 & 0.25 & 0.18 & 0.07 & 0.06 & 0.01 \\
\hline
\end{tabular}

Table 3

Specific rates (C-mmol/g-cell h) of glucose, xylose and oxygen (OUR) consumption and formation of carbon dioxide (CER), biomass, xylitol, glycerol, acetate and ethanol in the continuous cultivation of yeast $\mathrm{H} 2490$ on $27 \mathrm{~g} / \mathrm{L}$ xylose with $3 \mathrm{~g} / \mathrm{L}$ glucose (XYL/GLC3) and on $10 \mathrm{~g} / \mathrm{L}$ glucose (GLC) under anaerobic and aerobic conditions and of yeast $\mathrm{H} 2446$ on $30 \mathrm{~g} / \mathrm{L}$ xylose with $1,0.5,0.1$ and $0 \mathrm{~g} / \mathrm{L}$ glucose under aerobic conditions (XYL/GLC1; XYL/GLC0.5; XYL/GLC0.1; XYL)

\begin{tabular}{|c|c|c|c|c|c|c|c|c|c|}
\hline & Glucose & Xylose & OUR & CER & Biomass & Xylitol & Glycerol & Acetate & Ethanol \\
\hline \multicolumn{10}{|l|}{ Anaerobic } \\
\hline GLC & -27.2 & 0.00 & 0.00 & 8.60 & 1.85 & 0.00 & 2.88 & 0.66 & 10.57 \\
\hline XYL/GLC3 & -19.1 & -15.4 & 0.00 & 7.49 & 1.83 & 7.62 & 2.78 & 1.04 & 12.63 \\
\hline \multicolumn{10}{|l|}{ Aerobic } \\
\hline GLC & -7.22 & 0.00 & -4.19 & 4.26 & 1.86 & 0.00 & 0.00 & 0.81 & 0.48 \\
\hline XYL/GLC3 & -1.95 & -3.62 & -2.26 & 2.76 & 1.93 & 0.74 & 0.06 & 0.02 & 0.04 \\
\hline XYL/GLC1 & -1.18 & -5.31 & -1.91 & 2.28 & 1.95 & 0.63 & 0.55 & 0.14 & 0.03 \\
\hline XYL/GLC0.5 & -0.80 & -6.73 & -1.77 & 2.36 & 1.88 & 0.85 & 0.45 & 0.18 & 0.03 \\
\hline XYL/GLC0.1 & -0.11 & -8.39 & -0.84 & 2.61 & 1.77 & 1.05 & 0.65 & 0.29 & 0.05 \\
\hline XYL & 0.00 & -7.45 & -0.20 & 3.20 & 1.85 & 1.13 & 0.43 & 0.37 & 0.12 \\
\hline
\end{tabular}

rates of substrate utilization and metabolite production are presented in Table 3. Under aerobic conditions the specific carbon flux in was $5.6 \mathrm{C}-\mathrm{mmol} / \mathrm{h} \mathrm{g}$ on xyloseglucose mixture and $7.2 \mathrm{C}-\mathrm{mmol} / \mathrm{hg}$ on pure glucose. Under anaerobic conditions the respective rates were 35 and $27 \mathrm{C}-\mathrm{mmol} / \mathrm{hg}$. For the aerobic xylose-glucose fermentations approximately $65 \%$ of the utilized carbon was xylose, whereas under anaerobic conditions the xylose fraction was only $45 \%$. The specific oxygen utilization rate was $2.3 \mathrm{mmol} / \mathrm{hg}$ on xylose-glucose mixture, which was only around $50 \%$ of that on glucose $(4.2 \mathrm{mmol} / \mathrm{h} \mathrm{g})$. The respective carbon dioxide evolution rates were 2.8 and $4.3 \mathrm{mmol} / \mathrm{hg}$ with respiratory quotients of 1.2 and 1.0. Under anaerobic conditions the specific carbon dioxide evolution rates were 7.5 and $8.6 \mathrm{mmol} / \mathrm{hg}$ on the mixture and on glucose, respectively. The specific ethanol production rate was highest on the xylose-glucose mixture under anaerobic conditions $(12.6$ vs. $10.6 \mathrm{C}-\mathrm{mmol} / \mathrm{hg}$ on pure glucose). However, the corresponding ethanol yields vs. the total carbon utilized (see Table 4), were highest on pure glucose $(0.37$ vs. $0.39 \mathrm{C}-\mathrm{mol} / \mathrm{C}-\mathrm{mol})$. Yields of xylitol were 0.22 and $0.13 \mathrm{C}-\mathrm{mol} / \mathrm{C}-\mathrm{mol}$ under anaerobic and aerobic conditions, respectively. Under anaerobic conditions $50 \%$ of xylose was excreted as xylitol while under aerobic conditions the corresponding yield was $20 \%$.

The metabolic flux analysis was based on measurements of extracellular carbon dioxide, ethanol, glycerol, acetate and xylitol production and consumption of glucose, xylose and oxygen. For the aerobic case the results of the metabolic flux analysis are presented in Fig. 1 and for the anaerobic case in Fig. 2. The fluxes are presented as percentages of the total carbon utilized. The fluxes that showed the most significant differences under aerobic conditions were the flux from glucose-6phosphate to ribulose-5-phosphate $\left(r_{21}\right)$, the flux from glucose-6-phosphate to fructose-6-phosphate $\left(r_{2}\right)$, the fluxes from glyceraldehyde-3-phosphate to pyruvate $\left(r_{4-6}\right)$ and the flux from pyruvate to acetyl coenzyme 
Table 4

Yields (C-mol/C-mol) of carbon dioxide $\left(\mathrm{CO}_{2}\right)$, biomass, xylitol, glycerol, acetate and ethanol over total glucose/xylose in the continuous cultivation of yeast $\mathrm{H} 2490$ on $27 \mathrm{~g} / \mathrm{L}$ xylose with $3 \mathrm{~g} / \mathrm{L}$ glucose (XYL/GLC3) and on $10 \mathrm{~g} / \mathrm{L}$ glucose (GLC) under anaerobic and aerobic conditions and of yeast $\mathrm{H} 2446$ on $30 \mathrm{~g} / \mathrm{L}$ xylose with $1,0.5,0.1$ and $0 \mathrm{~g} / \mathrm{L}$ glucose under aerobic conditions (XYL/GLC1; XYL/GLC0.5; XYL/GLC0.1; XYL)

\begin{tabular}{|c|c|c|c|c|c|c|c|}
\hline & $\mathrm{CO}_{2}$ & Biomass & Xylitol & Glycerol & Acetate & Ethanol & SUM \\
\hline \multicolumn{8}{|l|}{ Anaerobic } \\
\hline GLC & 0.32 & 0.07 & 0.00 & 0.11 & 0.02 & 0.39 & 0.90 \\
\hline XYL/GLC3 & 0.22 & 0.05 & 0.22 & 0.08 & 0.03 & 0.37 & 0.97 \\
\hline \multicolumn{8}{|l|}{ Aerobic } \\
\hline GLC & 0.59 & 0.26 & 0.00 & 0.00 & 0.11 & 0.07 & 1.03 \\
\hline XYL/GLC3 & 0.50 & 0.35 & 0.13 & 0.01 & 0.00 & 0.01 & 1.00 \\
\hline XYL/GLC1 & 0.35 & 0.30 & 0.10 & 0.08 & 0.02 & 0.00 & 0.86 \\
\hline XYL/GLC0.5 & 0.31 & 0.25 & 0.11 & 0.06 & 0.02 & 0.00 & 0.76 \\
\hline XYL/GLC0.1 & 0.31 & 0.21 & 0.12 & 0.08 & 0.03 & 0.01 & 0.76 \\
\hline XYL & 0.43 & 0.25 & 0.15 & 0.06 & 0.05 & 0.02 & 0.95 \\
\hline
\end{tabular}

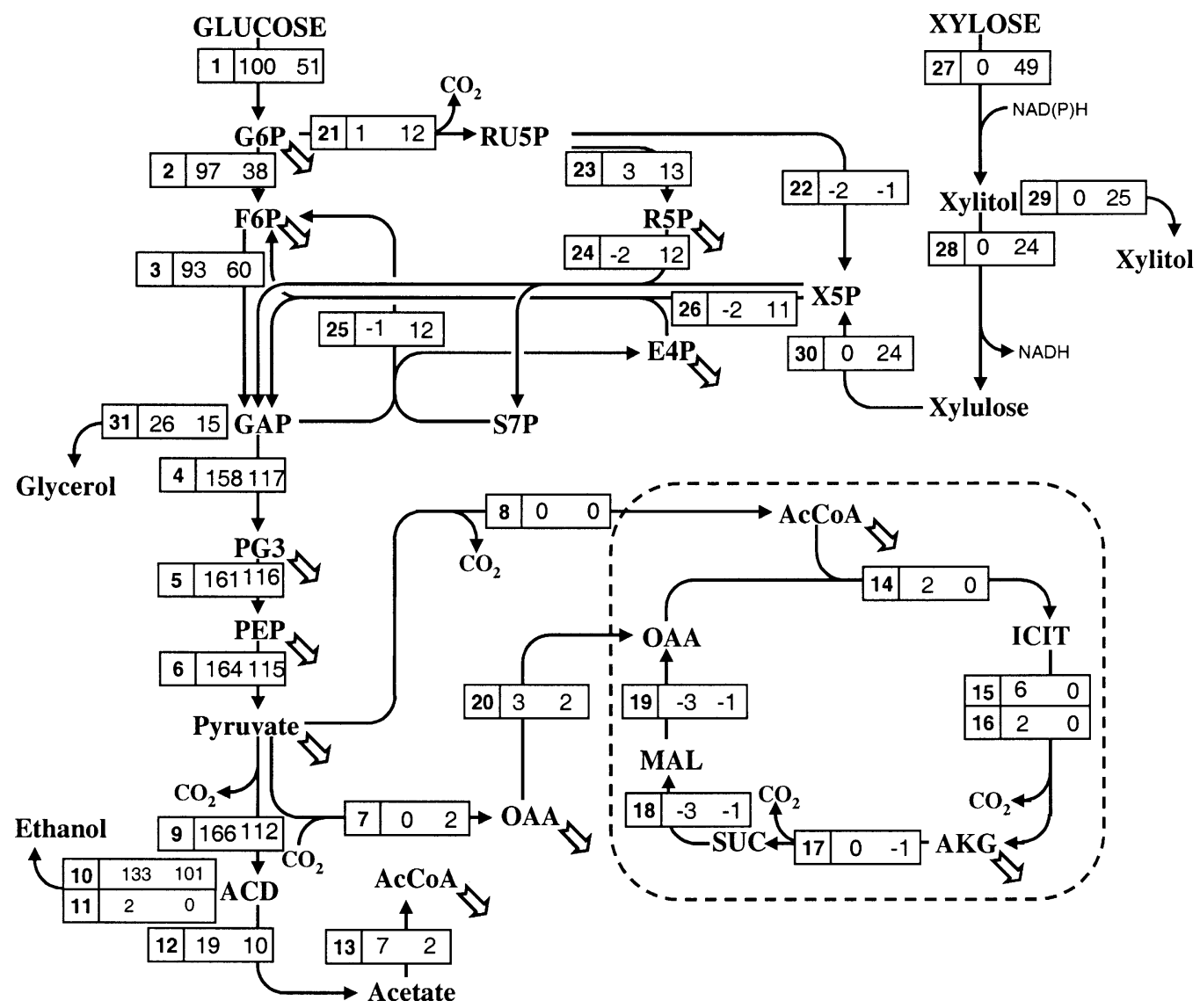

Fig. 2. The central carbon fluxes under anaerobic conditions on glucose $(10 \mathrm{~g} / \mathrm{L})$ and on xylose-glucose mixture $(27: 3 \mathrm{~g} / \mathrm{L})$ in continuous chemostat cultivations at the dilution rate of $0.05 \mathrm{~h}^{-1}$. In each box, the left-hand number identifies the reaction step (see Appendix A), the middle number shows the flux on glucose and the right-hand number the flux on xylose-glucose mixture. The flux units are as a percentage of the total sugar utilization. In the glucose-only cultivation the specific glucose flux in was $4.53 \mathrm{mmol} / \mathrm{h} \mathrm{g}$. In the xylose-glucose cultivation glucose flux in was $3.18 \mathrm{mmol} / \mathrm{h} \mathrm{g}$ and the xylose flux in $3.07 \mathrm{mmol} / \mathrm{h} \mathrm{g}$. Mitochondrial membrane is illustrated with a dashed line and the biomass-producing fluxes with the open arrows.

A $\left(r_{8}\right)$. The flux from glucose-6-phosphate to ribulose-5phosphate, which is the NADPH-producing oxidative branch of pentose phosphate pathway, increased almost tenfold on xylose-glucose mixture compared to pure glucose. On the xylose-glucose mixture the amount of glucose entering the cell cannot supplement this increase, which thus leads to a negative flux from fructose-6-phosphate to glucose-6-phosphate $\left(r_{2}\right)$. Due to the carbon lost in the above-mentioned NADPHproducing pathway, the total flux to pyruvate $\left(r_{6}\right)$ on 
xylose-glucose mixture was only around $60 \%$ of that on glucose. Consequently, the flux from pyruvate to intramitochondrial acetyl coenzyme $\mathrm{A}\left(r_{8}\right)$ and the following fluxes of citric acid cycle $\left(r_{14-19}\right)$ were reduced correspondingly. Under anaerobic conditions, the fluxes with greatest differences were the same as under aerobic conditions, namely the NADPH-producing flux from glucose-6-phosphate to ribulose-5-phosphate $\left(r_{21}\right)$ and the total flux to pyruvate $\left(r_{6}\right)$. However, since less xylose was used per glucose, the differences were not as striking as under aerobic conditions. The greatest difference between aerobic and anaerobic conditions, besides the non-operational citric acid cycle, was the flux from glucose-6-phosphate to fructose-6-phosphate $\left(r_{2}\right)$. The flux was clearly negative under aerobic conditions, but positive under anaerobic conditions. Also the total flux to pyruvate did not decrease as much under anaerobic as aerobic conditions. On xylose-glucose mixture under anaerobic conditions the flux to pyruvate was $70 \%$ of the flux on glucose whereas the same value under aerobic conditions was $60 \%$.

Obviously, the cofactor specificity of the XR-reaction plays a major role in the whole cofactor balance of the cell. Thus the model was solved using different ratios for the cofactor specificity of the XR-reaction ranging from 0 (only NADH specific) to 1 (only NADPH specific). The results for the most significant fluxes of the cultivation on $27: 3 \mathrm{~g} / \mathrm{L}$ xylose-glucose mixture are presented in Table 5. The increase in the NADPHspecificity of the XR-reaction led to increase in the NADPH-generating path, oxidative pentose phosphate pathway $\left(r_{21}\right)$. This resulted in a higher negative flux from fructose-6-phosphate $\left(r_{2}\right)$, and a lower flux to pyruvate $\left(r_{6}\right)$ and to the citric acid cycle $\left(r_{8}\right)$. Furthermore, due to higher NADPH-specificity, the net reaction of $\mathrm{XR}$ and $\mathrm{XDH}$ produced more cytosolic $\mathrm{NADH}$. Thus the shuttling of cytosolic NADH to mitochondrion and oxidative phosphorylation was increased $\left(r_{11}\right)$ as a result of higher NADPH-specificity of the XR reaction.

Table 5

The effect of cofactor ratio (NADPH:(NADPH + NADH)) of the xylose reductase (XR) reaction on selected central carbon fluxes under aerobic conditions on xylose-glucose mixture $(27: 3 \mathrm{~g} / \mathrm{L})$ in continuous chemostat cultivations at the dilution rate of $0.05 \mathrm{~h}^{-1}$. The values are presented in $\%$ of the total carbon utilization $(\mathrm{mmol} / \mathrm{mmol})$

\begin{tabular}{lrrrrr}
\hline Cofactor ratio of XR (NADPH) & 0.0 & 0.3 & 0.5 & 0.7 & 1.0 \\
\hline$r_{2} \mathrm{G} 6 \mathrm{P} \rightarrow \mathrm{F} 6 \mathrm{P}$ & -6 & -17 & -24 & -31 & -42 \\
$r_{21} \mathrm{G} 6 \mathrm{P} \rightarrow \mathrm{RU} 5 \mathrm{P}$ & 32 & 42 & 49 & 56 & 67 \\
$r_{6} \mathrm{PEP} \rightarrow \mathrm{PYR}$ & 109 & 106 & 104 & 101 & 98 \\
$r_{7} \mathrm{PYR} \rightarrow \mathrm{OAA}$ & 6 & 5 & 5 & 5 & 5 \\
$r_{8} \mathrm{PYR} \rightarrow \mathrm{AcCoA}$ & 71 & 67 & 65 & 62 & 58 \\
$r_{9} \mathrm{PYR} \rightarrow \mathrm{ACD}$ & 27 & 28 & 29 & 29 & 30 \\
$r_{11} \mathrm{ACD} \rightarrow \mathrm{ETH}(\mathrm{ADH} 3)$ & -110 & -127 & -139 & -151 & -168 \\
\hline
\end{tabular}

3.2. The effect of decreasing glucose level on metabolism of xylose

The experiments described above were complemented with a set of continuous cultivation of strain H2446 using various xylose-glucose mixtures, under aerobic conditions. The xylose level in the feed was maintained constant at $30 \mathrm{~g} / \mathrm{L}$, and to that glucose was added at one of the following levels: $1,0.5,0.1$ and $0 \mathrm{~g} / \mathrm{L}$. The dilution rates, gas flow rates, cultivation liquid volumes, glucose and xylose concentrations in feed media and oxygen and carbon dioxide levels in gas feed are presented in Table 1. The concentrations $(\mathrm{g} / \mathrm{L})$ of glucose, xylose, xylitol, glycerol, acetate and ethanol in the vessel and levels (\%) of oxygen and carbon dioxide in the gas outflow at pseudo-steady states are presented in Table 2. Specific rates of substrate utilization and metabolite production are presented in Table 3. The yields over total carbon utilized are presented in Table 4 . When the glucose level in the feed was reduced, the accumulation rates and yields of xylitol, glycerol, ethanol and carbon dioxide were increased. Simultaneously, the specific oxygen uptake rate was decreased. On the other hand the specific xylose utilization rate was highest when the glucose level in the feed was $0.1 \mathrm{~g} / \mathrm{L}$.

The selected results of metabolic flux analysis are presented in Fig. 3 as a function of the glucose amount in the feed. The fluxes are presented as percentages of the total carbon utilized. As compared to the fluxes that were most significant on glucose, the oxidative branch of pentose phosphate pathway $\left(r_{21}\right)$ now remained constant as the glucose level was decreased. The flux from glucose 6-phosphate to fructose 6-phosphate $\left(r_{2}\right)$ and the flux to pyruvate $\left(r_{6}\right)$ both decreased as the glucose level in the feed was decreased. Simultaneously the flux of the XKreaction from xylulose to xylulose 5-phosphate $\left(r_{30}\right)$ first increased along with the increasing xylose ratio, but at the lowest glucose levels $(<0.5 \mathrm{~g} / \mathrm{L}$ glucose) decreased rapidly back to the same level as on $3 \mathrm{~g} / \mathrm{L}$ glucose. The varying glucose level in the feed revealed the competition at the pyruvate branch-point between fluxes leading to acetaldehyde $\left(r_{9}\right)$ and mitochondrial acetyl-CoA $\left(r_{8}\right)$. The flux to acetyl-CoA is decreased at the gain of the flux to acetaldehyde as the glucose level in the feed is decreased. When the additional glucose level in the feed was $0.1 \mathrm{~g} / \mathrm{L}$, only $19 \%$ of the pyruvate was converted to acetyl-CoA and $80 \%$ to acetaldehyde, whereas the corresponding values for $3 \mathrm{~g} / \mathrm{L}$ were $65 \%$ and $30 \%$, respectively. Approximately $5 \%$ of the pyruvate was directed to oxaloacetate at all the other glucose levels but at the glucose level of $0.1 \mathrm{~g} / \mathrm{L}$ only $1 \%$ of pyruvate went to oxaloacetate.

The observation in the chemostat cultivation that the specific, in vivo xylose utilization rate was highest at the lowest glucose level in the feed $(0.1 \mathrm{~g} / \mathrm{L})$ was examined further. It has been postulated that the xylose uptake is 

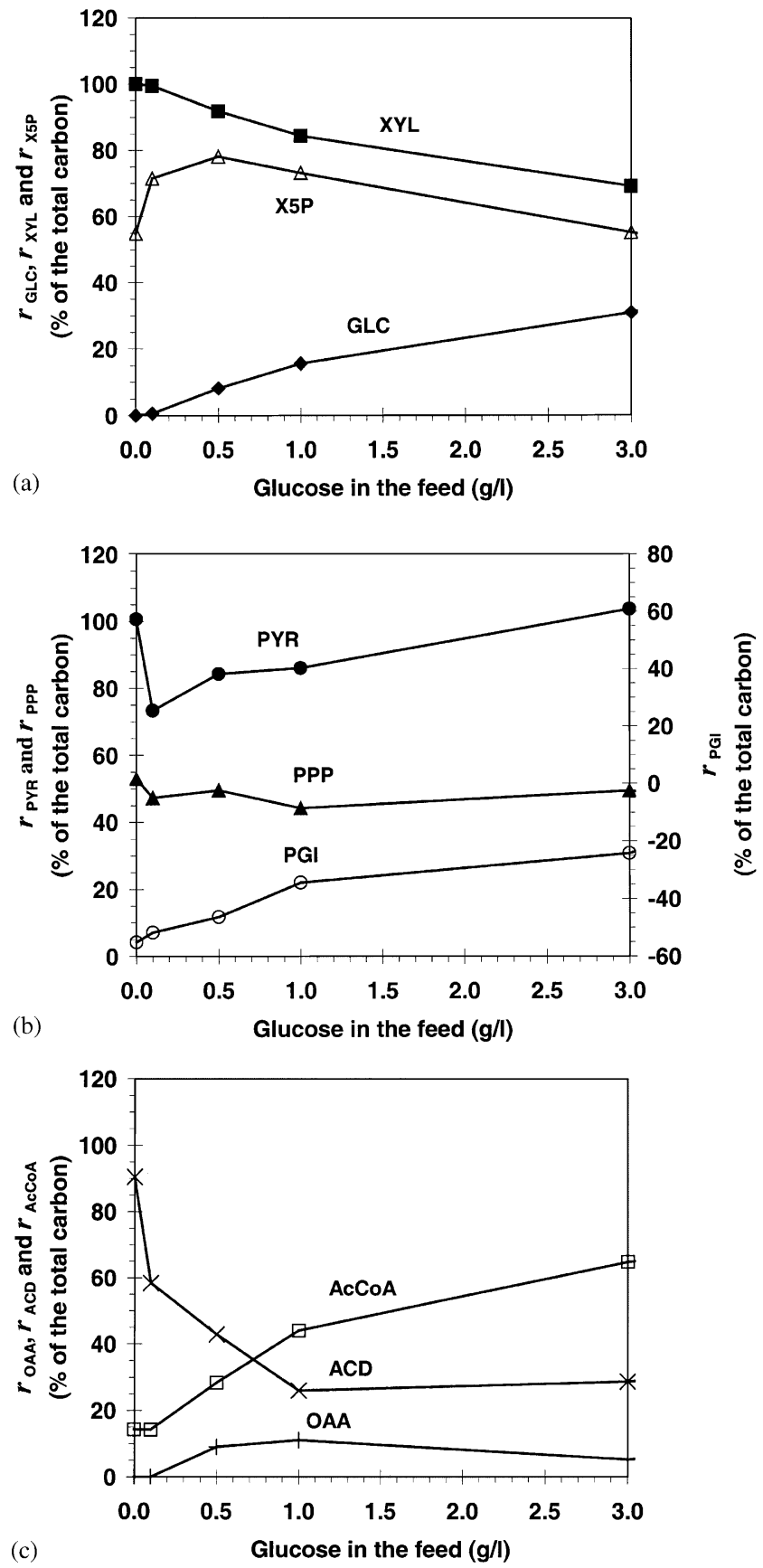

Fig. 3. The selected central carbon fluxes on $30 \mathrm{~g} / \mathrm{L}$ xylose with varying glucose levels $(0,0.1,0.5,1$ and $3 \mathrm{~g} / \mathrm{L})$ in continuous chemostat cultivations at the dilution rate of $0.05 \mathrm{~h}^{-1}$. Fluxes 1 (GLC in, $\left.\bullet\right), 27$ (XYL in, $\mathbf{\square}$ ), 30 (XUL to X5P, $\triangle$ ), 6 (PEP to PYR, ๑); 21 (G6P to Ru5P, $\mathbf{\Lambda}$ ), 2 (G6P to F6P, O) 7 (PYR to OAA, +), 8 (PYR to AcCoA, $\square$ ) and 9 (PYR to ACD, $\times$ ) are presented. The flux units are as a percentage of the total sugar utilization. The specific xylose and glucose fluxes in were in the ascending glucose order: 1.49 and 0.00 , 1.68 and $0.02,1.35$ and $0.13,1.06$ and $0.20,0.73$ and $0.32 \mathrm{mmol} / \mathrm{h} \mathrm{g}$.

both enhanced and inhibited by glucose (Cirillo, 1961; Does and Bisson, 1989; Grootjen et al., 1991; Ojamo, 1994). In order to study this, xylose uptake assays were performed with the cells grown in shake flask

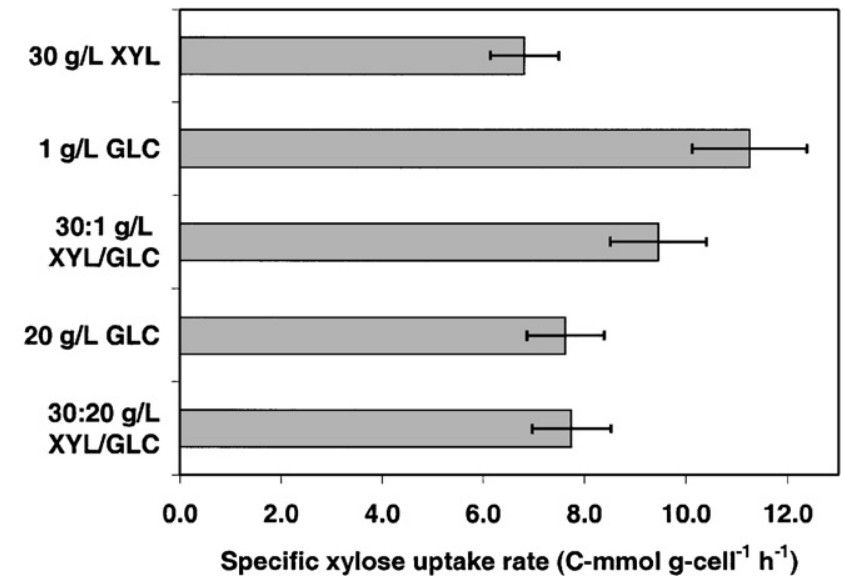

Fig. 4. The specific xylose uptake rates measured with $150 \mathrm{mM}{ }^{14} \mathrm{C}$ labeled xylose from the cells grown in shake flask cultivations on five different xylose-glucose mixtures for $3 \mathrm{~h}$. The xylose-glucose mixtures used in the media were: $30 \mathrm{~g} / \mathrm{L}$ xylose, $1 \mathrm{~g} / \mathrm{L}$ glucose, $30 \mathrm{~g} / \mathrm{L}$ xylose and $1 \mathrm{~g} / \mathrm{L}$ glucose, $20 \mathrm{~g} / \mathrm{L}$ glucose, and $30 \mathrm{~g} / \mathrm{L}$ xylose and $20 \mathrm{~g} / \mathrm{L}$ glucose

cultivations using ${ }^{14} \mathrm{C}$-labeled D-xylose. As postulated, the specific xylose uptake rate was highest for the cells grown on the lower glucose level $(1 \mathrm{~g} / \mathrm{L})$ or on the xylose-glucose mixture containing the same amount of glucose $(1 \mathrm{~g} / \mathrm{L})$ and $30 \mathrm{~g} / \mathrm{L}$ xylose. As shown in Fig. 4, xylose uptake rates on pure xylose were comparable to those on $20 \mathrm{~g} / \mathrm{L}$ glucose. However, the xylose uptake rate was found to be higher in the presence of small amounts of glucose. The xylose uptake rate was $9.5 \mathrm{C}$ $\mathrm{mmol} / \mathrm{hg}$ on xylose-glucose mixture $(30: 1 \mathrm{~g} / \mathrm{L})$ and $6.8 \mathrm{C}-\mathrm{mmol} / \mathrm{hg}$ on pure xylose. The highest xylose uptake rate was observed with the cells grown on $1 \mathrm{~g} /$ $\mathrm{L}$ glucose without xylose. The glucose concentrations after the $3 \mathrm{~h}$ shake flask cultivation on $1 \mathrm{~g} / \mathrm{L}$ glucose, $30: 1 \mathrm{~g} / \mathrm{L}$ xylose-glucose mixture, $20 \mathrm{~g} / \mathrm{L}$ glucose, and $20: 30 \mathrm{~g} / \mathrm{L}$ xylose-glucose mixture were $<0.2,3.1,99$ and $97 \mathrm{mM}$, respectively. Furthermore, inhibition effect of glucose on xylose uptake was studied by adding glucose $(0.1,0.5$ or $1 \mathrm{~g} / \mathrm{L})$ into the assay mixture along with the ${ }^{14} \mathrm{C}$-labeled xylose and the cells grown on $30: 1 \mathrm{~g} / \mathrm{L}$ xylose-glucose mixture. Thus the cells were grown and assayed in the presence of glucose. The specific uptake rates of xylose decreased as the glucose level in the assay mixture was increased. The measured in vitro xylose uptake rates are presented in Fig. 5 as a function of the glucose concentration in the assay. At zero-point the line is connected to the result from the cells grown on pure xylose instead of xylose-glucose mixture. This was done to simulate the conditions in the chemostat on pure xylose where the xylose utilization rate was significantly lower than the xylose uptake rate of the cells grown on xylose-glucose mixture. Fig. 5 presents also the in vivo xylose utilization rates in the chemostat cultivations at different feed glucose levels. To our satisfaction, the in vitro assayed xylose uptake rates correlated well with 


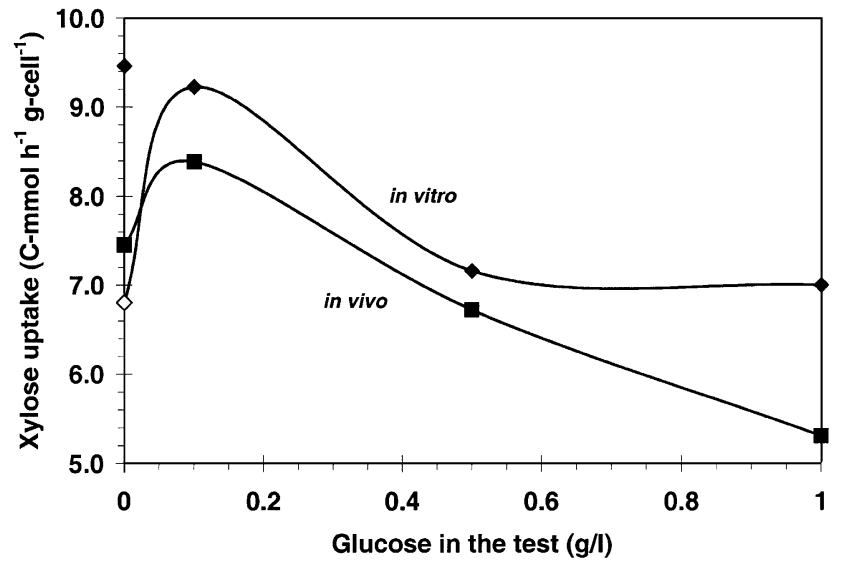

Fig. 5. The specific xylose utilization rates $(\boldsymbol{\square})$ from the chemostat cultivations with varying glucose levels $(1,0.5,0.1$ and $0 \mathrm{~g} / \mathrm{L}$ xylose and the specific xylose uptake rates $(\bullet)$ measured with ${ }^{14} \mathrm{C}$-labeled xylose from the cells grown in shake flask cultivations on $30: 1 \mathrm{~g} / \mathrm{L}$ xyloseglucose mixture for $3 \mathrm{~h}$. At the glucose level of $0 \mathrm{~g} / \mathrm{L}$ the uptake rate plot is connected to the value which was measured from the cells grown on pure $30 \mathrm{~g} / \mathrm{L}$ xylose in the shake flask cultivation $(\diamond)$ instead of the point of the cells grown on $30: 1 \mathrm{~g} / \mathrm{L}$ xylose-glucose mixture.

the measured, in vivo xylose consumption rates in the chemostat cultivations.

\section{Discussion}

The two-step oxidoreductase reaction of D-xylose to D-xylulose with xylose reductase and xylitol dehydrogenase requires NADPH and $\mathrm{NAD}^{+}$. The compensation of this cofactor imbalance has global effects on the overall metabolism, which can be subdivided in two categories pertinent to the pentose phosphate pathway together with the upper glycolysis, and the lower glycolysis with citric acid cycle and the pyruvate branch-point.

\subsection{Effects of cofactor imbalance on pentose phosphate pathway and upper glycolysis}

Most of the cytosolic NADPH in Saccharomyces is believed to be generated in the reactions from glucose 6phosphate to ribulose 5-phosphate, a route known as the oxidative branch of pentose phosphate pathway (Bruinenberg et al., 1983). The route is operated by three enzymes: glucose-6-phosphate dehydrogenase, 6-phosphogluconolactonase and 6-phosphogluconate dehydrogenase (Jeppsson et al., 2002; Miclet et al., 2001). According to our results, the activity of this pathway is increased significantly under aerobic conditions on a xylose-glucose mixture $(27: 3 \mathrm{~g} / \mathrm{L})$ compared to pure glucose. This leads to a negative flux from fructose 6phosphate to glucose 6-phosphate, thus, creating a futile cycle between glycolysis and pentose phosphate pathway. The added glucose alone cannot provide the flux needed for the NADPH generation. When the glucose level in the feed is decreased stepwise from 3 to $0 \mathrm{~g} / \mathrm{L}$ (3, $1,0.5,0.1$ and $0 \mathrm{~g} / \mathrm{L}$ ), the negative flux is further increased. The NADPH generation via this route leads to loss of carbon since 1 mole of carbon dioxide per 2 moles of NADPH is produced. The loss of carbon at the upper part of the metabolic network leaves less flux to lower glycolysis leading to pyruvate, the flux further decreasing when the glucose level is decreased. The above observation is consistent with the recent findings of Jeppsson and co-workers (Jeppsson et al., 2002), which illustrated that disruption of either GND1 (one of the isogenes of 6-phosphogluconate dehydrogenase), or ZWF1 (gene for glucose 6-phosphate dehydrogenase), resulted in higher ethanol yields (up to $0.41 \mathrm{~g} / \mathrm{g}$ ) and lower xylitol yields (down to $0.05 \mathrm{~g} / \mathrm{g}$ ), and also in a $84 \%$ lower xylose consumption rate. Both increased ethanol yields and the radical decrease in the xylose consumption rate can be explained by the loss of the NADPHgenerating futile cycle of the oxidative pentose phosphate pathway.

\subsection{Effects of cofactor imbalance at the pyruvate branch- point and citric acid cycle}

At the pyruvate branch-point slightly more pyruvate is directed to acetaldehyde on xylose-glucose mixture compared to pure glucose ( $34 \%$ vs. $27 \%$ ). This is at the expense of flux to acetyl-CoA and citric acid cycle $(53 \%$ vs. $57 \%$ ). The overall fluxes in the citric acid cycle on the xylose-glucose mixture $(27: 3 \mathrm{~g} / \mathrm{L})$ are only around $55 \%$ of the fluxes on glucose. The result gains further support by our results from the proteome analysis of the $27: 3 \mathrm{~g} / \mathrm{L}$ xylose-glucose mixture and corresponding $10 \mathrm{~g} / \mathrm{L}$ glucose cultivation's (Salusjärvi et al., 2003). Levels of some proteins of citric acid cycle were reduced in accordance to the flux analysis results presented here. The proteins identified were fumarase (Fum1p), isocitrate dehydrogenase subunits (Idh1p and Idh2p) and malate dehydrogenase (Mdhlp).

The observed lower flux in the citric acid cycle is mainly due to lower flux to pyruvate, but also there are some differences in the ratios between the fluxes going to acetaldehyde and intramitochondrial acetyl-CoA. The effect of more carbon going to acetaldehyde is further enhanced when the glucose level is reduced. The increased flux to acetaldehyde at the expense of intramitochondrial acetyl-CoA may simply result from the attempts to generate more cytosolic $\mathrm{NAD}^{+}$, used in the xylitol dehydrogenase reaction. Indeed, the flux from xylitol to xylulose decreased at the very lowest glucose levels $(0.1 \mathrm{~g} / \mathrm{L})$ revealing the deficiency of cytosolic $\mathrm{NAD}^{+}$. When glucose level in the feed decreased, the flux from xylulose to xylulose 5-phosphate first increased along with the increasing xylose ratio, but at the lowest glucose levels decreased rapidly. This indicates 
that there is sufficient NADPH for xylose reduction, but not sufficient $\mathrm{NAD}^{+}$for the oxidation of xylitol to xylulose. Another indication of sufficient amount of NADPH is that the fluxes of pentose phosphate pathway $\left(r_{21-26}\right)$ stay constant, mainly the NADPH-generating flux from glucose 6-phosphate to ribulose 5-phosphate $\left(r_{21}\right)$.

Under aerobic conditions the electron transfer chain and respiration convert mitochondrial NADH to $\mathrm{NAD}^{+}$. Respiration should thus provide the NAD ${ }^{+}$ for the XDH reaction in the cytosol. However, in steady state, the flux of NADH into the mitochondrion must be equal to the flux of $\mathrm{NAD}^{+}$out of the mitochondrion. Transport of NADH into the mitochondrion requires a shuttle system, an example of which is Adh3p, which according to our model operates in the reverse direction of Adh1p. Thus the NADH molecule itself does not go through the membrane, only the reducing equivalents. The reaction is also implemented in the model, which shows very high flux through the assumed NADH shuttle. According to our results, most of the mitochondrial NADH was produced by the citric acid cycle, but on xylose-glucose mixture $(27: 3 \mathrm{~g} / \mathrm{L}) \quad 35 \%$ and on glucose $28 \%$ was shuttled from cytosol. The limitation of cytosolic $\mathrm{NAD}^{+}$on xylose at the lowest glucose levels may result from inadequate shuttling of NADH to the mitochondrion. The results from the proteome analysis (Salusjärvi et al., 2003) give some basis for this assumption as well since several proteins linked to shuttling of reducing equivalents were expressed at higher levels on xylose-glucose mixture than on pure glucose. These proteins include Ald4p, Ald6p and Gpp1p. Other possible redox shuttles in addition to the Adh3pcatalyzed ethanol-acetaldehyde shuttle are glycerol-3phosphate shuttle, malate-oxaloacetate shuttle and malate-aspartate shuttle (Bakker et al., 2001; Barron et al., 1998; Overkamp et al., 2000). The shuttling of NADH from cytosol could be a major contributor also for the observed decrease in the activity of the TCA-cycle. If there is more NADH originating from the cytosol there is less need for NADH generation in the TCA-cycle.

\subsection{Anaerobiosis}

Under anaerobic conditions the effects of cofactor imbalance were not as prominent, since higher portion of carbon is coming from glucose and does not thus affect the redox balance as much as xylose does. Thus the fluxes, which showed a considerable change under aerobic conditions, namely the futile cycle through oxidative pentose phosphate pathway and the flux to pyruvate show only a minor change under anaerobic conditions. The oxidative phosphorylation is not in operation under anaerobic conditions, which affects the whole cellular cofactor balance. Under anaerobic conditions the cofactor NADH has to be regenerated in the fermentative pathways starting from pyruvate and as a result an increased production of ethanol and glycerol are normally observed. The need for the regeneration of NADH in the cytosol also increases the xylitol production since there is not enough $\mathrm{NAD}^{+}$ for the XDH-reaction. The highest theoretical yield of ethanol production from xylose was estimated by Lee and co-workers (Lee et al., 2001). From the aerobic results discussed above it was clear that a large part of carbon is lost in NADPH-generation for the XR reaction. Thus also under anaerobic conditions some carbon is lost as carbon dioxide, the carbon which will never reach ethanol and the production of which would generate $\mathrm{NAD}^{+}$required for the $\mathrm{XDH}$ reaction. Also Wahlbom (Wahlbom et al., 2001) have demonstrated the xylose metabolism under anaerobic conditions in a similar metabolic flux analysis study. Their results on $20 \mathrm{~g} / \mathrm{L}$ glucose and $15: 5 \mathrm{~g} / \mathrm{L}$ xylose-glucose mixture agree well with our results on $10 \mathrm{~g} / \mathrm{L}$ glucose and 27:3 g/L xylose-glucose mixture under anaerobic conditions. As an example, in both cases the flux from glucose-6-phosphate to ribulose-5-phosphate is higher on the mixture than on glucose only. Considering the differences in the substrate levels the results are very similar between the two studies, which demonstrates how reproducible the chemostat studies, and even these simple flux models, can be. The models used in this work and in the studies reported by Wahlbom and co-workers (Wahlbom et al., 2001; Wahlbom and Hahn-Hägerdal, 2002) are very similar. Both models were derived from the work done by Nissen and co-workers, and van Gulik and Heijnen (Nissen et al., 1997; van Gulik and Heijnen, 1995). One difference between our and Wahlbom's models was the NADH/NADPH specificity of the XRreaction. In our model we used one fixed ratio (1:1) for the specificity of $\mathrm{XR}$ in all conditions, whereas Wahlbom and co-workers used two fluxes for the reaction; one for each cofactor. In our conditions their approach favored the NADH-specific reaction, which hardly is the actual case. We tested the influence of changing the fixed NADH/NADPH ratio and the result of increasing the NADPH specificity was similar as decreasing the level of glucose in the feed. In order to study the question thoroughly the in vivo ratio of the NADH and NADPH should be measured.

\subsection{The effect of glucose at the uptake}

The effect of glucose on xylose uptake was tested in two different experiments. The chemostat experiments showed increasing specific xylose consumption in vivo at decreasing glucose levels, which has also been noticed before (Walfridsson et al., 1995). A confirming result was obtained from direct uptake experiments in vitro as glucose in the assay mixture decreased the xylose uptake rate with the same pattern as discovered in the chemostats. This is due to glucose with lower $K_{\mathrm{m}}$ values 
being the preferred substrate of hexose transporters compared to other substrates, especially xylose (Serrano and Delafuente, 1974). However, low levels of glucose have also a positive effect on xylose uptake.

Uptake of hexoses is facilitated by a series of carriers encoded by the family of $H X T$ genes. The genes $H X T 1-7$ are those with demonstrated physiological significance, but there are several additional hexose transporters whose role is not well known (at least HXT8-17, GAL2, $A G T 1, Y D L 247 w$ and YJR160c encoded transporter homologues) (Bisson et al., 1993; Boles and Hollenberg, 1997; Wieczorke et al., 1999). According to Reifenberg and co-workers the $K_{\mathrm{m}}$ values for glucose of the individual transporter are as follows: $50-100 \mathrm{mM}$ for HXt1p and Hxt3p, $10 \mathrm{mM}$ for Hxt2p and Hxt4p, 1$2 \mathrm{mM}$ for HXt6p and Hxt7p (Reifenberger et al., 1997). Furthermore, they suggest that at low glucose levels $H X T 2$ encodes for transporter with both high $\left(K_{\mathrm{m}}\right.$ $1.5 \mathrm{mM})$ and low affinity $\left(K_{\mathrm{m}} 60 \mathrm{mM}\right)$ for glucose (Reifenberger et al., 1997). There is only limited information available about the expression of the remaining $H X T$ genes (HXT8-17) or the kinetic properties of the transporters they encode (Özcan and Johnston, 1999).

It is still poorly understood how yeast senses xylose. A report suggests that xylose-grown Candida contains enzyme activities participating in gluconeogenesis, which places xylose amongst the nonfermentable substrates (Granström et al., 2002). This is supported also by our own, yet unpublished results in $S$. cerevisiae. Thus, if xylose indeed is sensed as a nonfermentable carbon source by the cells, transporters in the absence of glucose and in the presence of xylose would be Hxt6p and Hxt7p, and possibly Hxt5p, since $H X T 6$ and $H X T 7$ are expressed on nonfermentable carbon sources (Dlugai et al., 2001), and HXT5 is expressed under starvation (Buziol et al., 2002). Further, possible transporters in the presence of low glucose are Hxt2p, Hxt3p, Hxt4p, Hxt6p and Hxt7p (Liang and Gaber, 1996; Özcan and Johnston, 1995, 1996, 1999), which are likely to contribute also to uptake of xylose on the mixtures of xylose and glucose. The difference between xylose only and the mixture would therefore be the presence of Hxt2p, Hxt3p and Hxt4p on the mixture of xylose and glucose. It is thus tempting to speculate that those or either of them are the transporters responsible for the observed higher xylose uptake rate on the mixtures of xylose and glucose. However, it must be said that more experiments are required with individual transporters, including also the transporters encoded by the genes HXT8-17, to examine their xylose transfer properties.

The assayed in vitro uptake rates were more than $0.5 \mathrm{C}-\mathrm{mmol} / \mathrm{hg}$ higher than the in vivo consumption rates measured in chemostats except at xylose only when the in vivo rate was higher than the in vitro rate. The in vivo rate being higher than the in vitro rate could indicate that the degradation of the signaling proteins like Snf3p (Özcan et al., 1998) or the transporter proteins expressed at low glucose levels, was not completed in all cells thus enabling a higher uptake rate for xylose on the chemostat feed with no glucose.

\section{Conclusions}

The different cofactor specificities of the two-step oxidoreductase reaction of xylose create a futile cycle between pentose phosphates, fructose-6-phosphate and glucose-6-phosphate with serious consequences. Let us envision the metabolic network as two sections, upstream and downstream, the upstream consisting of the hexose and pentose phosphates and the downstream of triose phosphates and organic acids. At the upstream, there is a route for NADPH generation, oxidative pentose phosphate pathway, but it consumes carbon in the form of evolved carbon dioxide reducing the flow of carbon downstream to pyruvate. Hence, NADPH generation is not a problem for the cell but it causes problems further downstream since the main $\mathrm{NAD}^{+}$. generating routes start from pyruvate. The flow of carbon is preferentially (and too easily even) used for the generation of NADPH, leaving a lesser amount for the generation of $\mathrm{NAD}^{+}$. Thus, at the end, generation of $\mathrm{NAD}^{+}$becomes a bottleneck for xylose metabolism. Furthermore, under aerobic conditions the shuttling of $\mathrm{NADH}$ into the mitochondrion is likely to play a limiting role in xylose metabolism when no glucose is provided. Metabolic engineering of xylose metabolism would benefit on finding a mechanism for production of $\mathrm{NADPH}$ upstream in metabolism through a route, which would not result in loss of carbon. For example simultaneous deletion of glucose-6-phospate dehydrogenase encoding gene (Jeppsson et al., 2002) and expression of a partly NADPH-dependent glyceraldehyde 3-phosphate dehydrogenase encoding gene could direct the flow of carbon directly towards pyruvate and ethanol without the loss of carbon (Verho et al., 2002; Verho et al., manuscript in preparation). By using solely metabolic flux analysis it was not possible to study the effects of xylose uptake or pentose phosphate reactions, since their role as a limiting step originates from their kinetic properties such as $K_{\mathrm{m}}$ values for uptake and Gibbs free energies for pentose phosphate pathway and thus cannot be studied in the present steady-state model. However, application of the metabolic flux analysis to data from a series of cultivations where a factor, i.e., glucose level in the feed, was changed, proved useful in providing correlations against the changing glucose level. The metabolic flux analysis helped to concretize and visualize the tentative thoughts about the metabolic fluxes in xylose metabolism. This confirms some earlier assumptions and observations, and also brings up new questions in the metabolism of xylose. 


\section{Acknowledgments}

The financial support of Academy of Finland and National Technology Agency (Tekes) are gratefully acknowledged. Authors like to thank Eila Leino for the indispensable help in the laboratory and Dr. John Londesborough, Dr. Hannu Maaheimo, Dr. Peter Richard, and M. Sci Mervi Toivari for fruitful and instructive discussions and important comments on the manuscript. The first author is also grateful for Dr. Heikki Ojamo and Professor Matti Leisola for additional encouragement and instructions in preparing the manuscript.

\section{Appendix A. S. cerevisiae metabolic network model}

\section{Glycolysis}

(1) GLC (23) + ATP (11) $\rightarrow$ G6P (21) + ADP (5)

(2) G6P (21) $\rightarrow$ F6P (19)

(3) F6P (19) + ATP (11) $\rightarrow$ 2GAP (22) + ADP (5)

(4) GAP (22) + NAD (36) + ADP (5) $\rightarrow$ PG3 (20) + NADH (38) + ATP (11)

(5) PG3 (20) $\rightarrow$ PEP (49)

(6) PEP (49) + ADP (5) $\rightarrow$ PYR (55) + ATP (11)

\section{Pyruvate branch-point}

(7) $\mathrm{PYR} \quad(55)+\mathrm{ATP} \quad$ (11) $+\mathrm{CO}_{2} \quad$ (14) $\rightarrow \mathrm{OAA} \quad$ (45) + ADP (5)

(8) PYR (55) + NADm (37) + COA (15) $\rightarrow$ ACCOAm + $\mathrm{CO}_{2}(14)+\mathrm{NADHm}(39)$

(9) PYR (55) $\rightarrow$ ACD (3) $+\mathrm{CO}_{2}$ (14)

\section{Fermentative pathways}

(10) ACD (3) + NADH (38) $\rightarrow$ ETH (18) + NAD (36)

(11) ACD (3) + NADHm (39) $\rightarrow$ ETH (18) + NADm (37)

(12) ACD (3) + NADP (40) $\rightarrow$ ACE (4) + NADPH (42)

(13) ACE (4) + COA (15) +2 ATP (11) $\rightarrow$ ACCOA (1) $+2 \mathrm{ADP}(5)$

Citric acid cycle

(14) OAAm (46) + ACCOAm (2) $\rightarrow$ ICIT $(30)+$ COA (15)

(15) $\mathrm{ICIT}(30)+\mathrm{NADm}(37) \rightarrow \mathrm{AKG}(6)+\mathrm{CO}_{2}(14)+$ $\mathrm{NADHm}(39)$

(16) ICIT $\quad(30)+\mathrm{NADPm} \quad(41) \rightarrow \mathrm{AKG} \quad(6)+\mathrm{CO}_{2}$ (14) + NADPHm (43)

$\begin{array}{lll}\text { (17) } \mathrm{AKG} & \text { (6) + NADm (37) }+\mathrm{ADP} & \text { (5) } \rightarrow \mathrm{SUC}\end{array}$ (61) + ATP (11) $+\mathrm{CO}_{2}$ (14) + NADHm (39)

(18) SUC (61) $+0.5 \quad \mathrm{NADm} \quad(37) \rightarrow$ MAL (34) +0.5 NADHm (39)
(19) MAL (34) + NADm (37) $\rightarrow$ OAAm NADHm (39)

(20) OAA (45) + NADm (37) + NADH (38) $\rightarrow$ OAAm (46) + NADHm (39) + NAD (36)

\section{Pentose phosphate pathway}

(21) G6P $\quad(21)+2 \mathrm{NADP} \quad(40) \rightarrow \mathrm{RU} 5 \mathrm{P} \quad(58)+\mathrm{CO}_{2}$ $(14)+2$ NADPH (42)

(22) RU5P (58) $\rightarrow$ XU5P (68)

(23) RU5P (58) $\rightarrow$ R5P (56)

(24) R5P (56) + XU5P (68) $\rightarrow$ S7P (59) + GAP (22)

(25) S7P (59) + GAP (22) $\rightarrow$ F6P (19) + E4P (17)

(26) XU5P (68) + E4P (17) $\rightarrow$ F6P (19) + GAP (22)

Xylose

(27) XYL (70) +0.5 NADPH (42) + 0.5 NADH (38) $\rightarrow$ $\mathrm{XOL}(66)+0.5$ NADP (40)+ 0.5 NAD (36)

(28) XOL (66) + NAD (36) $\rightarrow$ XUL (69) + NADH (38)

(29) XOL (66) $\rightarrow$ XOL (E) (67)

(30) XUL (69) + ATP (11) $\rightarrow$ XU5P (68) + ADP (5)

Glycerol

(31) GAP (22) + NADH (38) $\rightarrow$ GOL (28) + NAD (36)

\section{BIOMASS COMPONENTS}

Polysaccharides

(32) 0.16667 G6P (21) +0.16667 ATP (11) $\rightarrow$ TREGLY $(53)+0.16667$ ADP (5)

(33) 0.16667 F6P (19) +0.16667 ATP (11) $\rightarrow$ MANNO $(54)+0.16667$ ADP (5)

Fatty acids

A separate amino acid production matrix $N$ with dimension $m$ metabolites $\times 2$ fatty acid fluxes for palmiate and oleate

(FAT-1) 8 ACCOA (1)+15 ATP (11) 15 NADPH $(42)+\mathrm{O}_{2}(44) \rightarrow \mathrm{PAL}(48)+8 \mathrm{COA}(15)+15$ ADP (5) + 15 NADP (40)

(FAT-2) 9 ACCOA (1) + 17 ATP (11) +17 NADPH $(42)+\mathrm{O}_{2}(44) \rightarrow$ OLE (47) +9 COA (15) +17 ADP (5) + 17 NADP (40)

(34) 0.5 PAL (48) +0.5 OLE (47) $\rightarrow$ FAT (71)

Amino acids and protein

A separate amino acid production matrix $N$ with dimensions $m$ metabolites $\times 20$ a/a fluxes

(AA-1) PYR (55) + NADPH (42) $\rightarrow$ ALA (7) + NADP (40) 
(AA-2) AKG (6) +4 NADPH (42) +7 ATP (11) $+\mathrm{NAD}(36) \rightarrow$ ARG (8) + 4 NADP $(40)+7$ ADP (5) + NADH (38)

(AA-3) OAA (45) + 1 NADPH (42) +3 ATP (11) $\rightarrow$ ASN (9) + 1 NADP (40) +3 ADP (5)

$(\mathrm{AA}-4)$ OAA $(45)+1$ NADPH $(42) \rightarrow$ ASP $(10)+1$ NADP (40)

(AA-5) PG3 (20) + 4 NADPH (42) + 7 ATP (11) + NAD $\quad(36) \rightarrow$ CYS $\quad(16)+4 \quad \mathrm{NADP} \quad(40)+7$ ADP (5) + NADH (38)

(AA-6) AKG (6) + 1 NADPH (42) $\rightarrow$ GLU (25) + 1 NADP (40)

(AA-7) AKG (6) + 1 NADPH (42) + 1 ATP (11) $\rightarrow$ GLN (24) + 1 NADP (40) + 1 ADP (5)

(AA-8) PG3 (20) + 1 NAD (36) + 2 NADP $(40) \rightarrow$ GLY (26) + 1 NADH (38) + 2 NADPH (42) + $\mathrm{CO}_{2}(14)$

(AA-9) R5P (56) + 4 NADPH (42) +6ATP (11) + 3 $\mathrm{NAD}(36)+\mathrm{CO}_{2}(14) \rightarrow \mathrm{HIS}(29)+4 \mathrm{NADP}$ $(40)+6$ ADP (5) + 3 NADH (38)

(AA-10) OAA (45) + PYR (55) + 5 NADPH (42) + 2 ATP $(11) \rightarrow \operatorname{ILE}(31)+5$ NADP (40) +2 ADP (5)

(AA-11) ACCOA (1)+2 PYR (55) +2 NADPH $(42)+1$ NAD $\quad(36) \rightarrow$ LEU $\quad(32)+2$ NADP $(40)+1$ NADH (38)

(AA-12) ACCOA (1) + AKG (6) + 4 NADPH (42) + 2 ATP (11) + 2 NAD (36) $\rightarrow$ LYS (33) + 4 NADP $(40)+2 \mathrm{ADP}(5)+2 \mathrm{NADH}(38)$

(AA-13) OAA $(45)+11 \quad$ NADPH $(42)+7 \quad$ ATP $(11)+\mathrm{CO} 2 \quad(14) \rightarrow \mathrm{MET} \quad(35)+11 \quad \mathrm{NADP}$ (40) +7 ADP (5)

(AA-14) 2 PEP (49) + E4P (17) + 2 NADPH (42) + ATP $(11) \rightarrow$ PHE (50) + 2 NADP (40) + ADP (5)

$(\mathrm{AA}-15)$ AKG (6) + 3 NADPH (42) +1 ATP $(11) \rightarrow$ PRO (51) + 3 NADP (40) + 1 ADP (5)

(AA-16) PG3 (20) + 1 NADPH (42) + 1 NAD (36) $\rightarrow$ SER (60) + 1 NADP (40) + 1 NADH (38)

$($ AA-17) OAA (45) + 3 NADPH (42) +2 ATP (11) $\rightarrow$ THR (62) + 3 NADP (40) + 2 ADP (5)

(AA-18) PEP (49)+E4P (17) + PG3 (20) + 3 NADPH $(42)+5$ ATP $(11)+2$ NAD (36) $\rightarrow$ TRP $(63)+3$ NADP (40) + 5 ADP (5) + 2 NADH (38)

(AA-19) 2 PEP (49) + E4P (17) + 2 NADPH (42) + 1 ATP $\quad(11)+1 \quad$ NAD $\quad(36) \rightarrow$ TYR $\quad(64)+2$ NADP (40) + 1 ADP (5) + 1 NADH (38)

(AA-20) 2 PYR (55) + 2 NADPH (42) $\rightarrow$ VAL $(65)+2$ NADP (40)

(35) 0.047 ALA (7) +0.056 ARG (8) +0.0254 ASN (9) +0.1016 ASP (10) +0.009 CYS (16) +0.1072 GLU (25) +0.0268 GLN (24)+0.056 GLY $(26)+0.091$ HIS (29) +0.052 ILE $(31)+0.079$ LEU (32) +0.031 LYS (33) +0.047 MET $(35)+0.040$ PHE $(50)+0.043$ PRO (51) +0.052 SER $\quad(60)+0.014$ THR $(62)+0.040 \quad$ TRP (63) +0.065 TYR $(64)+0.017$ VAL $(65)+4$ ATP (11) $\rightarrow 4.8248$ PROT (52) +4 ADP (5)
Table 6

Metabolites in the flux model

\begin{tabular}{|c|c|c|}
\hline$m$ & Abbreviation & Metabolite \\
\hline 1 & ACCOA & Acetyl-CoA \\
\hline 2 & ACCOAm & $\begin{array}{l}\text { Acetyl-CoA, } \\
\text { mitochondrial }\end{array}$ \\
\hline 3 & $\mathrm{ACD}$ & Acetaldehyde \\
\hline 4 & $\mathrm{ACE}$ & Acetate \\
\hline 5 & ADP & Adenosine- $5^{\prime} \mathrm{diP}$ \\
\hline 6 & $\mathrm{AKG}$ & 2-Ketoglutarate \\
\hline 7 & ALA & Alanine \\
\hline 8 & ARG & Arginine \\
\hline 9 & ASN & Asparagine \\
\hline 10 & ASP & Aspartate \\
\hline 11 & ATP & Adenosine- $5^{\prime}$ triP \\
\hline 12 & BIOM & Biomass \\
\hline 13 & CMPUMP & $\begin{array}{l}\text { Cytidine- } 5^{\prime}-\mathrm{P} \text { and } \\
\text { Uridine- } 5^{\prime}\end{array}$ \\
\hline 14 & $\mathrm{CO}_{2}$ & Carbon dioxide \\
\hline 15 & $\mathrm{COA}$ & Coenzyme-A \\
\hline 16 & CYS & Cysteine \\
\hline 17 & E4P & Erythrose-4'-P \\
\hline 18 & ETH & Ethanol \\
\hline 19 & F6P & Fructose- $6^{\prime} \mathrm{P}$ \\
\hline 20 & PG3 & 3-Phosphoglycerate \\
\hline 21 & G6P & Glucose- $6^{\prime}-\mathrm{P}$ \\
\hline 22 & GAP & Glyceraldehyde-3'-P \\
\hline 23 & GLC & Glucose \\
\hline 24 & GLN & Glutamine \\
\hline 25 & GLU & Glutamate \\
\hline 26 & GLY & Glycine \\
\hline 27 & GMPAMP & $\begin{array}{l}\text { Guanosine }-5^{\prime} \mathrm{P} \text { and } \\
\text { Adenosine- } 5^{\prime}-\mathrm{P}\end{array}$ \\
\hline 28 & GOL & Glycerol \\
\hline 29 & HIS & Histidine \\
\hline 30 & ICIT & Isocitrate \\
\hline 31 & ILE & Isoleucine \\
\hline 32 & LEU & Leucine \\
\hline 33 & LYS & Lysine \\
\hline 34 & MAL & Malate \\
\hline 35 & MET & Methionine \\
\hline 36 & NAD & $\begin{array}{l}\text { Nicotinamide adenine } \\
\text { dinucleotide }\end{array}$ \\
\hline 37 & NADm & NAD, mitochondrial \\
\hline 38 & $\mathrm{NADH}$ & NAD, reduced \\
\hline 39 & NADHm & NADH, mitochondrial \\
\hline 40 & NADP & $\begin{array}{l}\text { Nicotinamide adenine } \\
\text { dinucleotide phosphate }\end{array}$ \\
\hline 41 & NADPm & NADP, mitochondrial \\
\hline 42 & NADPH & NADP, reduced \\
\hline 43 & NADPHm & NADPH, mitochondrial \\
\hline 44 & $\mathrm{O}_{2}$ & Oxygen \\
\hline 45 & OAA & Oxaloacetate \\
\hline 46 & OAAm & $\begin{array}{l}\text { Oxaloacetate, } \\
\text { mitochondrial }\end{array}$ \\
\hline 47 & OLE & Oleate \\
\hline 48 & PAL & Palmitoleate \\
\hline 49 & PEP & Phosphoenol pyruvate \\
\hline 50 & PHE & Phenyl alanine \\
\hline 51 & PRO & Proline \\
\hline 52 & PROT & Protein \\
\hline 53 & TREGLY & Trehalose, glycogen... \\
\hline 54 & MANNO & Mannose... \\
\hline 55 & PYR & Pyruvate \\
\hline 56 & R5P & Ribose- $5^{\prime} \mathrm{P}$ \\
\hline 57 & RNA & Ribonucleic acid \\
\hline
\end{tabular}


Table 6 (continued)

\begin{tabular}{lll}
\hline$m$ & Abbreviation & Metabolite \\
\hline 58 & RU5P & Ribulose-5'-P \\
59 & S7P & Sedoheptulose-7'P \\
60 & SER & Serine \\
61 & SUC & Succinate \\
62 & THR & Threonine \\
63 & TRP & Tryptophan \\
64 & TYR & Tyrosine \\
65 & VAL & Valine \\
66 & XOL & Xylitol \\
67 & XOL $($ E) & Xylitol, extracellular \\
68 & XU5P & Xylulose-5'-P \\
69 & XUL & Xylulose \\
70 & XYL & Xylose \\
71 & FAT & Fatty acids \\
\hline
\end{tabular}

\section{Nucleotides and RNA}

A separate nucleotide production matrix $N$ with dimensions $m$ metabolities $\times 2$ fluxes
(NTD-1) R5P (56) + PG3 (20) + 2 NADPH (42) + 11 $\mathrm{ATP} \quad(11)+3 \quad \mathrm{NAD} \quad(36)+\mathrm{CO}_{2} \quad(14) \rightarrow$ GMPAMP (27) + 2 NADP (40)+ 11 ADP (5) + 3 NADH (38)

(NTD-2) R5P (56) + OAAm (46) + 1 NADPH (42) + 6 ATP $\quad(11) \rightarrow$ CMPUMP $\quad(13)+1 \quad$ NADP (40) + 6 ADP (5)

(36) 0.466 GMPAMP (27) +0.534 CMPUMP $(13)+3.2279 \quad$ ATP $\quad(11) \rightarrow 9.466 \quad$ RNA
$(57)+3.2279 \operatorname{ADP}(5)$

\section{BIOMASS}

(37) 0.47003 PROT (52)+0.20 TREGLY (53)+ 0.05234 RNA $(57)+0.00688$ FAT $(71)+0.00266$ GOL $(28)+0.13$ MANNO (54) $\rightarrow$ BIOM (12)

\section{Maintenance}

(38) $\operatorname{ATP}(11) \rightarrow \operatorname{ADP}(5)$

\section{Oxidative phosphorylation}

(39) NADHm (39) $+0.5 \mathrm{O}_{2}(44)+1$ ADP (5) $\rightarrow 1$ ATP (11) + NADm (37)

The metabolites in the flux model are given in Table 6.

\section{References}

Bakker, B.M., Bro, C., Kötter, P., Luttik, M.A., van Dijken, J.P., Pronk, J.T., 2000. The mitochondrial alcohol dehydrogenase
Adh3p is involved in a redox shuttle in Saccharomyces cerevisiae. J. Bacteriol. 182, 4730-4737.

Bakker, B.M., Overkamp, K.M., van Maris, A.J., Kötter, P., Luttik, M.A., van Dijken, J.P., Pronk, J.T., 2001. Stoichiometry and compartmentation of NADH metabolism in Saccharomyces cerevisiae. FEMS Microbiol. Rev. 25, 15-37.

Barron, J.T., Gu, L., Parrillo, J.E., 1998. Malate-aspartate shuttle, cytoplasmic NADH redox potential, and energetics in vascular smooth muscle. J. Mol. Cell. Cardiol. 30, 1571-1579.

Bisson, L.F., Coons, D.M., Kruckeberg, A.L., Lewis, D.A., 1993. Yeast sugar transporters. Crit. Rev. Biochem. Mol. Biol. 28, 259-308.

Boles, E., Hollenberg, C.P., 1997. The molecular genetics of hexose transport in yeasts. FEMS Microbiol. Rev. 21, 85-111.

Boles, E., Gohlmann, H.W., Zimmermann, F.K., 1996. Cloning of a second gene encoding 5-phosphofructo-2-kinase in yeast, and characterization of mutant strains without fructose-2,6-bisphosphate. Mol. Microbiol. 20, 65-76.

Bruinenberg, P.M., van Dijken, J.P., Sheffers, W.A., 1983. A theoretical analysis of NADPH production and consumption in yeasts. J. Gen. Microbiol. 129, 953-964.

Buziol, S., Becker, J., Baumeister, A., Jung, S., Mauch, K., Reuss, M., Boles, E., 2002. Determination of in vivo kinetics of the starvation-induced Hxt5 glucose transporter. FEMS Yeast Res. 2, 283-291.

Christianson, T.W., Sikorski, R.S., Dante, M., Shero, J.H., Hieter, P., 1992. Multifunctional yeast high-copy-number shuttle vectors. Gene 110, 119-122.

Cirillo, V.P., 1961. Transport of nonfermentable sugars across the yeast cell membrane. Membrane Transport Metab, Prague, pp. 343-351.

Dlugai, S., Hippler, S., Wieczorke, R., Boles, E., 2001. Glucosedependent and -independent signaling functions of the yeast glucose sensor Snf3. FEBS Lett. 505, 389-392.

Does, A.L., Bisson, L.F., 1989. Characterization of xylose uptake in the yeasts Pichia heedii and Pichia stipitis. Appl. Environ. Microbiol. 55, 159-164.

Eliasson, A., Christensson, C., Wahlborn, C.F., Hahn-Hägerdal, B., 2000. Anaerobic xylose fermentation by recombinant Saccharomyces cerevisiae carrying XYL2, XYL2, and XKS1 in mineral medium chemostat cultures. Appl. Environ. Microbiol. 66, 3381-3386.

Gietz, R.D., Sugino, A., 1988. New yeast-Escherichia coli shuttle vectors constructed with in vitro mutagenized yeast genes lacking six-base pair restriction sites. Gene 74, 527-1425534.

Gietz, D., St. Jean, A., Woods, R.A., Schiestl, R.H., 1992. Improved method for high efficiency transformation of intact yeast cells. Nucl. Acids Res. 20, 1425.

Granström, T.B., Aristidou, A.A., Jokela, J., Leisola, M., 2000. Growth characteristics and metabolic flux analysis of Candida milleri. Biotechnol. Bioeng. 70, 197-207.

Granström, T.B., Aristidou, A.A., Leisola, M., 2002. Metabolic flux analysis of Candida tropicalis growing on xylose in an oxygen limited chemostat. Metab. Eng. 4, 248-256.

Grootjen, D.R.J., Van der Lans, R.G.J.M., Luyben, K.C.A.M., 1991. Conversion of glucose/xylose mixtures by Pichia stipitis under oxygen-limited conditions. Enzyme Microb. Technol. 13, $648-654$.

Hill, J., Donald, K.A., Griffiths, D.E., Donald, G., 1991. DMSOenhanced whole cell yeast transformation. Nucl. Acids Res. 19, 5791.

Jeffries, T.W., 1981. Fermentation of xylulose to ethanol using xylose isomerase and yeasts. Proc. Third Symposium on Biotechnology in Energy Production and Conservation, Gatlinburg, Tennessee, 12 15 May 1981. Scott, C.D. (Ed.). John Wiley \& Sons, Inc, New York. Biotechnol. Bioeng. Symp. 315-324. 
Jeffries, T.W., 1990. Fermentation of D-xylose and cellobiose. In: Verachert, H., De Mot, R. (Eds.), Yeast-Biotechnology and Biocatalysis. Marcel Dekker, New York.

Jeppsson, M., Johansson, B., Hahn-Hägerdal, B., Gorwa-Grauslund, M., 2002. Reduced oxidative pentose phosphate pathway flux in recombinant xylose-utilizing Saccharomyces cerevisiae strains improves the ethanol yield from xylose. Appl. Environ. Microbiol. 68, 1604-1609.

Kötter, P., Amore, R., Hollenberg, C.P., Ciriacy, M., 1990. Isolation and characterization of the Pichia stipitis xylitol dehydrogenase gene, XYL2, and construction of a xylose-utilizing Saccharomyces cerevisiae transformant. Curr. Gen. 18, 493-500.

Kötter, P., Ciriacy, M., 1993. Xylose fermentation by Saccharomyces cerevisiae. Appl. Microbiol. Biotechnol. 38, 776-783.

Lee, T.-H., Kim, M.-Y., Ryu, Y.-W., Seo, J.-H., 2001. Estimation of theoretical yield for ethanol production from D-xylose by recombinant Saccharomyces cerevisiae using metabolic pathway synthesis algorithm. J. Microbiol. Biotechnol. 11, 384-388.

Liang, H., Gaber, R.F., 1996. A novel signal transduction pathway in Saccharomyces cerevisiae defined by Snf3-regulated expression of HXT6. Mol. Biol. Cell 7, 1953-1966.

Maaheimo, H., Pitkänen, J.-P., Aristidou, A., Salusjärvi, L., Szyperski, T., Penttilä, M. ${ }^{13} \mathrm{C}$-NMR metabolic flux profiling of Saccharomyces cerevisiae growing on glucose or xylose. Manuscript in preparation.

Miclet, E., Stoven, V., Michels, P.A., Opperdoes, F.R., Lallemand, J.Y., Duffieux, F., 2001. NMR spectroscopic analysis of the first two steps of the pentose-phosphate pathway elucidates the role of 6-phosphogluconolactonase. J. Biol. Chem. 276, $34840-34846$.

Nissen, T.L., Schulze, U., Nielsen, J., Villadsen, J., 1997. Flux distributions in anaerobic, glucose-limited continuous cultures of Saccharomyces cerevisiae. Microbiology 143, 203-218.

Ojamo, H., 1994. Yeast xylose metabolism and xylitol production. VTT Publ., No. 176, 91p., Technical Research Centre of Finland (VTT), Espoo, Finland.

Olsson, L., Hahn-Hägerdal, B., 1996. Fermentation of lignocellulosic hydrolysates for ethanol production. Enzyme Microb. Technol. 18, 312-321.

Overkamp, K.M., Bakker, B.M., Kötter, P., van Tuijl, A., de Vries, S., van Dijken, J.P., Pronk, J.T., 2000. In vivo analysis of the mechanisms for oxidation of cytosolic NADH by Saccharomyces cerevisiae mitochondria. J. Bacteriol. 182, 2823-2830.

Özcan, S., Johnston, M., 1995. Three different regulatory mechanisms enable yeast hexose transporter $(H X T)$ genes to be induced by different levels of glucose. Mol. Cell. Biol. 15, 1564-1572.

Özcan, S., Johnston, M., 1996. Two different repressors collaborate to restrict expression of the yeast glucose transporter genes HXT2 and HXT4 to low levels of glucose. Mol. Cell. Biol. 16, 5536-5545.

Özcan, S., Johnston, M., 1999. Function and regulation of yeast hexose transporters. Microbiol. Mol. Biol. Rev. 63, 554-569.

Özcan, S., Dover, J., Johnston, M., 1998. Glucose sensing and signaling by two glucose receptors in the yeast Saccharomyces cerevisiae. ЕMBO J. 17, 2566-2573.

Prior, B.A., Kötter, P., 1997. Pentose utilization by yeasts. In: Zimmermann, F.K., Entian, K.-D. (Eds.), Yeast Sugar Metabolism: Biochemistry, Genetics, Biotechnology and Applications. Technomic, Basel, pp. 561.

Reifenberger, E., Boles, E., Ciriacy, M., 1997. Kinetic characterization of individual hexose transporters of Saccharomyces cerevisiae and their relation to the triggering mechanisms of glucose repression. Eur. J. Biochem. 245, 324-561333.
Ruohonen, L., Aalto, M.K., Keränen, S., 1995. Modifications to the ADH1 promoter of Saccharomyces cerevisiae for efficient production of heterologous proteins. J. Biotechnol. 39, 193.

Salusjärvi, L., Poutanen, M., Pitkänen, J.-P., Koivistoinen, H., Aristidou, A., Kalkkinen, N., Ruohonen, L., Penttilä, M., 2003. Proteome analysis of recombinant xylose-fermenting Saccharomyces cerevisiae. Yeast 20, 295-314.

Serrano, R., 1977. Energy requirements for maltose transport in yeast. Eur. J. Biochem. 80, 97-102.

Serrano, R., Delafuente, G., 1974. Regulatory properties of the constitutive hexose transport in Saccharomyces cerevisiae. Mol. Cell. Biochem. 5, 161-193171.

Singh, A., Mishra, P., 1995. Microbial Pentose Utilization-Current Applications in Biotechnology. Elsevier, Amsterdam, p. 416.

Stephanopoulos, G., Nielsen, J., Aristidou, A., 1998. Metabolic Engineering: Principles \& Methodologies. Academic Press, San Diego, p. 669.

Stryer, L., 1995. Biochemistry. W.H. Freeman \& Co., New York, p. 1064.

Toivari, M.H., Aristidou, A., Ruohonen, L., Penttilä, M., 2001. Conversion of xylose to ethanol by recombinant Saccharomyces cerevisiae. Importance of xylulokinase (XKS1) and oxygen availability. Metab. Eng. 3, 236-249.

Ueng, P.P., Hunter, C.A., Gong, C.-S., Tsao, G.T., 1981. D-xylulose fermentation in yeasts. Biotechnol. Lett. 3, 315-320.

Van Gulik, W.M., Heijnen, J.J., 1995. A metabolic network stoichiometry analysis of microbial growth and product formation. Biotechnol. Bioeng. 48, 681-698.

Verho, R., Richard, P., Jonson, P.H., Sundqvist, L., Londesborough, J., Penttilä, M., 2002. Identification of the first fungal NADPGAPDH from Kluyveromyces lactis. Biochemistry 41, 13833-13838.

Verho, R., Richard, P., Londesborough, J., Penttilä, M. Engineering the redox cofactor regeneration for improved pentose fermentation in Saccharomyces cerevisiae. Manuscript in preparation.

Wahlbom, C.F., Hahn-Hägerdal, B., 2002. Furfural, 5-hydroxymethyl furfural, and acetoin act as external electron acceptors during anaerobic fermentation of xylose in recombinant Saccharomyces cerevisiae. Biotechnol. Bioeng. 78, 172-178.

Wahlbom, C.F., Eliasson, A., Hahn-Hägerdal, B., 2001. Intracellular fluxes in a recombinant xylose-utilizing Saccharomyces cerevisiae cultivated anaerobically at different dilution rates and feed concentrations. Biotechnol. Bioeng. 72, 289-296.

Walfridsson, M., Hallborn, J., Penttilä, S., Keränen, S., HahnHägerdal, B., 1995. Xylose-metabolizing Saccharomyces cerevisiae strains overexpressing the TKL1 and TAL1 genes encoding the pentose phosphate pathway enzymes transketolase and transaldolase. Appl. Environ. Microbiol. 61, 4184-4190.

Walfridsson, M., Bao, X., Anderlund, M., Lilius, G., Bulow, L., Hahn-Hägerdal, B., 1996. Ethanolic fermentation of xylose with Saccharomyces cerevisiae harboring the Thermus thermophilus xylA gene, which expresses an active xylose (glucose) isomerase. Appl. Environ. Microbiol. 62, 4648-4651.

Walfridsson, M., Anderlund, M., Bao, X., Hahn-Hägerdal, B., 1997. Expression of different levels of enzymes from the Pichia stipitis XYL1 and XYL2 genes in Saccharomyces cerevisiae and its effects on product formation during xylose utilization. Appl. Microbiol. Biotechnol. 48, 218-224.

Wang, P.Y., Schneider, H., 1980. Growth of yeasts on D-xylulose. Can. J. Microbiol. 26, 1165-1168.

Wieczorke, R., Krampe, S., Weierstall, T., Freidel, K., Hollenberg, C.P., Boles, E., 1999. Concurrent knock-out of at least 20 transporter genes is required to block uptake of hexoses in Saccharomyces cerevisiae. FEBS Lett. 464, 123-128. 